\title{
Sn-Bi(-Ga) TIM Alloys: Microstructure, Tensile Properties, Wettability and Interfacial Reactions
}

\author{
VÍTOR COVRE EVANGELISTA DA SILVA, ${ }^{1}$ \\ GUILHERME LISBOA DE GOUVEIA, ${ }^{1}$ \\ RODRIGO ANDRÉ VALENZUELA REYES, ${ }^{1}$ AMAURI GARCIA, ${ }^{2}$ \\ and JOSÉ EDUARDO SPINELLI 『1,3 \\ 1.-Department of Materials Engineering, Federal University of São Carlos, São Carlos, \\ SP 13565-905, Brazil. 2.-Department of Manufacturing and Materials Engineering, University \\ of Campinas UNICAMP, Campinas, SP 13083-860, Brazil. 3.-e-mail: spinelli@ufscar.br
}

In the present study, the main purpose is to examine the quality of the interface formed between either binary $\mathrm{Sn}-\mathrm{Bi}$ or ternary Sn-Bi-2wt.\%Ga Thermal Interface Material-TIM alloys and a copper $(\mathrm{Cu})$ substrate. The characteristics of the formed intermetallic compound (IMC) films were analyzed in the as-soldered joints, as well as during isothermal heat treatments at $100^{\circ} \mathrm{C}$ for long periods of time. Thermo-Calc computations were also used in return for a better comprehension of the mechanisms involved, including, for instance, those related to the presence of $\mathrm{Ga}$ within the interdendritic regions. This can be explained by the increase in the Ga-amount in the liquid-phase with the progress of solidification. In an effort to address the wettability issue, the contact angles between the molten alloy and the $\mathrm{Cu}$ substrate were also determined. Finally, tensile tests were performed in order to evaluate the effects of the minor Ga additions in the alloy's overall mechanical properties. Despite unsound alloy mechanical properties, gallium $(\mathrm{Ga})$ additions effectively suppress the formation of the CuSn intermetallic by replacing it with a $\mathrm{Cu}_{9} \mathrm{Ga}_{4}$ IMC layer in the as-soldered material, which grew with less deleterious morphology and finer thicknesses.

Key words: Solder alloys, thermal interface material-TIM, microstructure, interfacial reaction, wettability and tensile properties

\section{INTRODUCTION}

Gordon E. Moore's findings, at the end of the $70 \mathrm{~s}$, offered support to the claim that component density and performance of integrated circuits would double every year. ${ }^{1}$ Almost 10 years after this statement, Moore revised his calculations, concluding that these characteristics would double every 2 years. ${ }^{2}$ On a logical basis, there is no compelling reason to argue that this is nothing more than empirical observations. Although this may be true, this law was considered to be unabated for more than

(Received January 17, 2019; accepted May 9, 2019;

published online May 20, 2019)
40 years, as it was stated by Thompson and Parthasarathy. ${ }^{3}$ Both authors support that this rate was only possible because of a tremendous progress in production techniques, pushed by financial capital and government's investments.

In the last year, Williams discussed the question "What's next?"4 as some recent studies seem to delineate intricate constraints in this incredible evolution. Whatever the case may be, there is overwhelming evidence for the notion that the microelectronics revolution came up with a tremendous cost in terms of thermal control. ${ }^{5-7}$ There have been no dissenters to the view that the increase in component density would also induce a rise in the heat generation. In 2003, Gwinn and $\mathrm{Webb}^{8}$ stated that the power dissipation's increase in the Pentium 
4 with respect to the Pentium 2 (from $33 \mathrm{~W}$ to $80 \mathrm{~W}$ ) meant a rise of the heat flux by a factor of "6.1".

With this in mind, Razeeb et al. ${ }^{7}$ demonstrated that an effective heat dissipation is crucial to ensure reliable operation and to enhance the lifetime of these components. The most common setup can be described as a central processor unit (CPU) attached to a heat sink by a certain pressure. In an effort to maximize this heat dissipation, the heat sink is normally composed of $\mathrm{Cu}$, which has one of the highest thermal conductivity values among metals. However, when these two pieces are attached, only a small mechanical contact area will indeed exist. Sarvar et al. ${ }^{6}$ pointed out that this may happen as a result of the micro-scale surface roughness and waviness of the surfaces. In fact, Razeeb et al. ${ }^{7}$ argue that the actual mechanical contact may be as low as $1-2 \%$ of the total surface. ${ }^{7}$

The most important consequence is a reduction in the effective heat dissipation, as the gaps formed in this process are normally filled by air. Because of its low conductivity value, the air entrapped in between the surfaces creates a thermal contact resistance. Some of the aspects of this interface may be characterized as a Newtonian heat conduction, as it is further described by Garcia and Prates. ${ }^{9}$ Although prominent, mechanical techniques to increase the actual contact area are not so effective. Therefore, in order to enhance the heat dissipation, these gaps must be filled by a material with a higher thermal conductivity value. This filler material is denominated as a thermal interface material (TIM).

In a recent market analysis,${ }^{10}$ the BCC Research group's report highlighted that "the TIM global market is forecasted to grow at a compound annual growth rate of $7.4 \%$ to reach nearly US $\$ 1.1$ billion in 2020 ". Razeeb et al. ${ }^{7}$ showed that several types of TIM can be utilized, for example, polymer composite-based gels, greases, carbon-based materials and various metal-based films. Although polymer-based TIMs represent almost $80 \%$ of the market, solders are considered more appropriate if considered for more demanding applications. The underlying argument in favor of this statement is based upon the solders' high thermal conductivity values, i.e., 20 $80 \mathrm{~W} /(\mathrm{mK}){ }^{6}$

Granted that, solder alloys may present poor thermal fatigue resistance. One explanation is the formation of a thin intermetallic film that would degrade its thermal conductivity and mechanical properties. ${ }^{11}$ Given the centrality of this issue, the $\mathrm{Sn}-\mathrm{Bi}$ alloys have gained attention, as they present a good compromise between thermal fatigue resistance and thermal conductivity. ${ }^{12}$ On the other hand, these alloys do not present a good wettability, which may significantly increase the interface's thermal resistance. ${ }^{7}$

Lin et al. ${ }^{13}$ stated that minor additions of $\mathrm{Ga}$ could suppress the formation of $\mathrm{Cu}_{6} \mathrm{Sn}_{5}$ and $\mathrm{Cu}_{3} \mathrm{Sn}$, which are two deleterious phases with respect to the joint's mechanical resistance. This could be explained by the formation of another intermetallic compound (IMC), i.e., $\mathrm{Cu}_{9} \mathrm{Ga}_{4}$, which is, apparently, less detrimental. Although minor Ga addition seems to effectively suppress IMCs formations between the liquid solder and the $\mathrm{Cu}$ substrate, there is insufficient research concerning the evolution of this $\mathrm{GaCu}$ IMC under service conditions, that is, under practical temperatures. Furthermore, there is an absence of studies emphasizing the mechanical and wetting behavior of Ga-containing alloys. Another important aspect to be explored involves the utilization of design concepts by thermodynamic computations. The use of thermodynamic tools may describe the microstructural evolution during solidification of Sn-Bi-Ga alloys. Simulated aspects may involve transformation temperatures, temperature ranges, proportions of intermetallic phases and various variant and invariant reactions along solidification.

In the present study, the main issue is examining the quality of the interface between the Snxwt.\%Bi(-2wt.\%Ga) alloys and the $\mathrm{Cu}$ substrate. The characteristics of the formed IMC films were analyzed not only in the as-soldered joints but also in the heat-treated samples. Thermo-Calc computations were also used so that a more complete comprehension of the mechanisms involved could be attained. All formed microstructures were interpreted in the light of equilibrium and Scheil computations. Wetting angles and spreadability of the four tested Sn-Bi(-Ga) alloys were determined against the $\mathrm{Cu}$ substrate. Finally, mechanical properties will be outlined for non-modified and Gamodified Sn-Bi alloys.

\section{MATERIALS AND METHODS}

\section{Alloy Processing}

Firstly, the alloys were manufactured inside an induction furnace using commercial purity elements. The prepared compositions were: Sn40wt.\%Bi, Sn-40wt.\%Bi-2wt.\%Ga, Sn-58wt.\%Bi and $\mathrm{Sn}-58 \mathrm{wt} . \% \mathrm{Bi}-2 \mathrm{wt} . \% \mathrm{Ga}$. As a side note, the $\mathrm{Ga}$ was added at the end of the process, as its low melting point could be related to a greater loss with respect to the other elements. Secondly, after the melting temperature was attained, the homogenization of the molten alloy was assured by the convection currents induced by the furnace into the melt. Finally, the molten alloy was poured into a graphite mold, producing two ingots for each pre-determined composition. These ingots were utilized in the production of samples for the wettability tests.

In an attempt to better investigate the quality evolution of the solder/Cu interface, the experimental activities were divided into three parts. Each part is related to an important aspect, which shall be further described in its specific subsection. The first part examines the transformation temperatures and the alloys' microstructures. Issues regarding the wettability problem and the IMC formation 
were examined in a second part of this study. Finally, in the third step, tensile tests were performed in order to directly analyze minor $\mathrm{Ga}$ additions and their effects on the tensile properties. A schematic illustration in Fig. 1 provides a general idea of the experimental steps with some detailing information included.
The transformation temperatures determined in this part were the liquidus and eutectic temperatures of each alloy. These values are extremely important in order to establish the soldering process parameters. With this in mind, the measurements were extracted by a J-type thermocouple inserted into the molten bath contained by a $\mathrm{SiC}$ refractory crucible inside the furnace. A temperature device
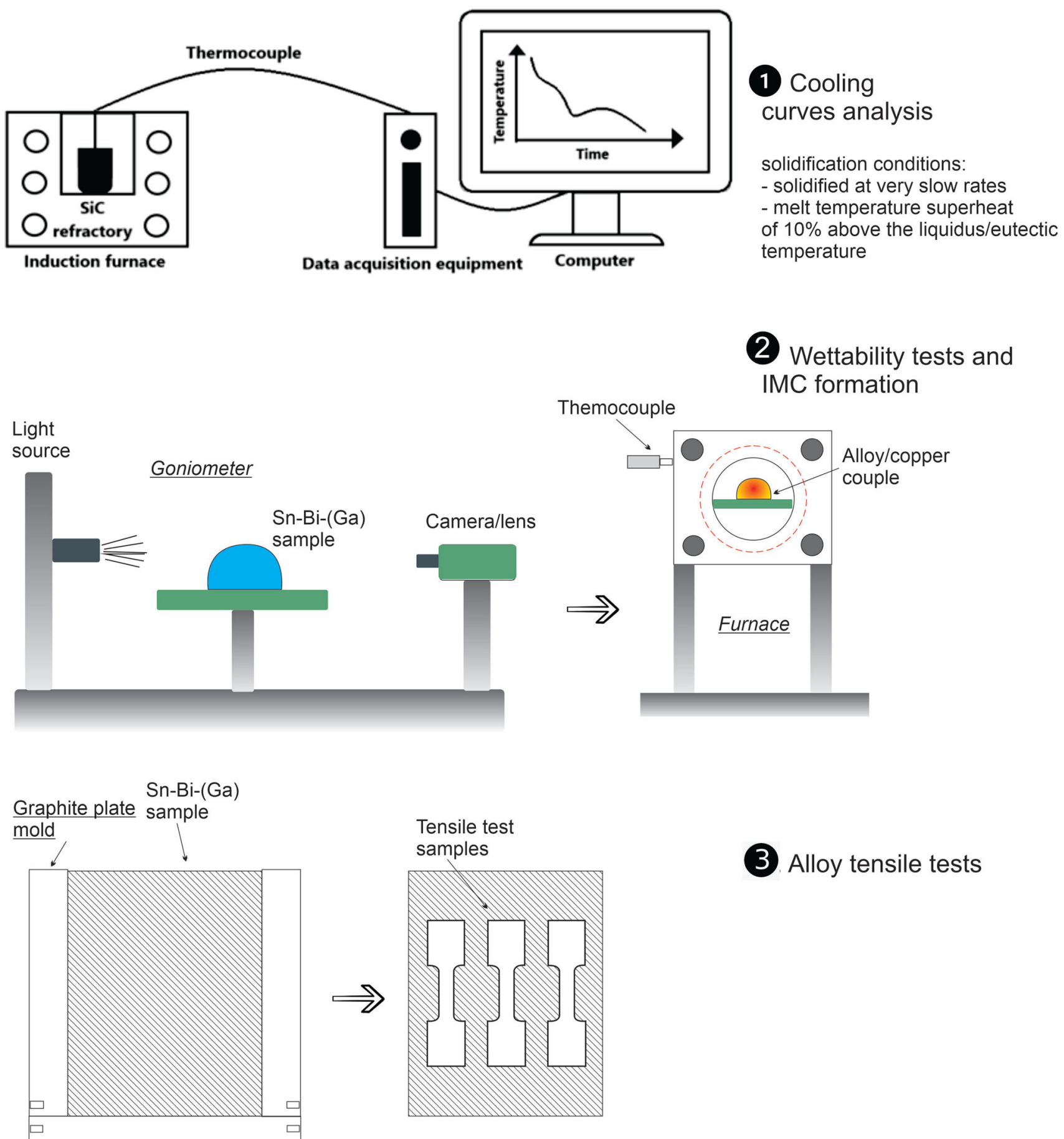

(3) Alloy tensile tests

Fig. 1. Sketch of the experimental methods used in the present investigation, which are 1. cooling curves to determine the alloys' transformation temperatures, 2. wettability test as well as IMC formation during heat treatment and 3 . tensile tests of the $\mathrm{Sn}-\mathrm{Bi}$-(Ga) alloys. 
permitted very accurate data acquisition of $5 \mathrm{~Hz}$ on the thermocouple for each generated cooling curve. The inner SiC refractory surface was covered with a layer of alumina-silica insulating paste in order to minimize radial heat losses and to assure the purge of the molten alloy. This setup permits a very slow cooling rate to be attained, which is a key parameter in order to attain equilibrium conditions.

This method represents a viable alternative for differential scanning calorimetry (DSC) and has already been used in previous studies. ${ }^{14-16}$ The thermocouples provided data about the temperature evolution with respect to time, which can be analyzed by Gibbs' rule of phases. ${ }^{9}$ The change in the number of phases coexisting in the system influences the temperature variation slope. In this way, these slope variations may be used to determine the characteristic temperatures. Other studies in the literature emphasize that a cooling rate of $1^{\circ} \mathrm{C} / \mathrm{min}\left(0.017^{\circ} \mathrm{C} / \mathrm{s}\right)$ is low enough in order to obtain close-to-equilibrium transformation temperatures in DSC. ${ }^{17,18}$ The present experimental setup allows cooling rates of about $0.02^{\circ} \mathrm{C} / \mathrm{s}$ to be attained, thus permitting near thermodynamic equilibrium to be reached.

After the cooling was finished, samples were extracted from the ingots produced in this process. These samples were subjected to metallographic preparation and have their microstructure evaluated by optical microscopy-OM (Olympus - model 41GX) and scanning electron microscopy-SEM (Philips XL-30 FEG). The etching solution was composed of $2 \mathrm{~mL} \mathrm{HCl}, 10 \mathrm{~mL} \mathrm{FeCl} l_{3}$ and $100 \mathrm{~mL}$ $\mathrm{H}_{2} \mathrm{O}$. In order to reveal the microstructure, the samples were submerged for a few seconds $(5-15 \mathrm{~s})$ into the etching solution.

\section{Experiments Following Interfacial Reactions}

With the purpose of measuring the contact angle $(\theta)$, cylinder bars with $4.0 \mathrm{~mm}$ of diameter were extracted from each ingot using machining operations. At the end of the process, samples with $4.0 \mathrm{~mm}$-height were cut out from the machined bars. Thereafter, the samples were coated by an adequate flux for testing. After, a coated sample was placed on the $\mathrm{Cu}$ substrate. It is well known that the surface roughness may influence the quality of the solder joint. Therefore, before the start of the wettability measurements, the $\mathrm{Cu}$ substrates were polished sequentially with $\mathrm{SiC}$ papers up to a 1200 mesh surface finish.

The wettability tests were performed in a Goniometer Krüss DSHAT HTM Reetz GmbH model. The contact angle between the solder and $\mathrm{Cu}$ substrate was defined as the average of the measured right and left angles, provided by a computational method called "tangent-2". The contact angle was measured uninterruptedly every $15 \mathrm{~s}$. Prior to the start of the test, an argon gas atmosphere was pumped and maintained in order to ensure a suitable purge throughout the equipment.
Concerning the thermal cycle, standard parameters were established. At first, a constant heating rate of $10^{\circ} \mathrm{C} / \mathrm{min}$ was imposed up to $20 \%$ above the liquidus temperature of each alloy. The superheat temperature was maintained for $25 \mathrm{~min}$, followed by natural cooling inside the furnace up to $120^{\circ} \mathrm{C}$. When this temperature was achieved, in order to avoid an undesired heat-treatment at this stage, the samples were quenched in water. For each sample, at least three tests were executed using the conditions described above.

The procedure proposed by Santos et al. and Silva et al. ${ }^{19-21}$ was implemented in order to assess the contact angle results. Two different periods of time across the experimental data are considered as of prime importance. They refer to the first $15 \mathrm{~s}$ after the complete melting of the sample during the wettability test (i.e., $\theta_{\mathrm{I}}$-initial contact angle); and the final $45 \mathrm{~s}$ of the imposed temperature stage (i.e., $\theta_{\mathrm{E}}$-equilibrium contact angle). The first value represents the contact angle between the solder and the molten alloy as soon as the solder melts. On the other hand, the mean value of the second period may represent the contact angle of a modified substrate due to IMC formation on the solder/substrate interface.

Other important information that could be determined is the spreading area. This measurement is executed by comparing the initial and final areas of the solders after the thermal cycle. On the whole, the initial area is calculated with respect to the cylinder diameter and the final diameter is determined by area calculations using the Image $J$ software. The as-soldered samples after the wettability tests were collected and investigated with emphasis on their microstructures and reaction layers.

The experiments proceed following additional steps. First, the samples already subjected to the wettability measurements were identified regarding the alloy's composition and the desired heat-treatment time. Two different periods of an imposed isothermal heat-treatment at $100^{\circ} \mathrm{C}$ were chosen, which are: 120 and $360 \mathrm{~h}(\mathrm{~h})$. This temperature value tries to induce a faster IMC growth, which would be normally achieved after a long time under the normal electronic component's thermal cycle. Moreover, this temperature is similar to the procedures applied in a previous work made by Yang et al. ${ }^{22}$ in which the duration of isothermal heattreatment was as long as $800 \mathrm{~h}$.

Another research work describes a procedure that uses an even higher temperature, i.e., $120^{\circ} \mathrm{C} .^{23}$ For high heat-treatment temperatures, extreme caution must be taken considering the normal fluctuations of furnace temperature, as they could overcome the Sn-Bi eutectic temperature. With this in mind, prior to the start of the isothermal treatment, a calibration of the furnace was carried out and the temperatures were monitored during the beginning of the heat-treatment. 
After the heat-treatment, the samples were cut and subjected to a metallographic procedure. In order to analyze the microstructure and the IMC layer, several methods were applied. Those include $\mathrm{OM}$ and SEM, which were used to examine the solder/substrate microstructure as well as the quality of the interface. The microstructure was revealed using the same etching solution previously mentioned. Energy dispersive x-ray spectroscopy (EDS) analysis was performed in return for identifying the phases as well as determining the distribution of the elements across the solder/substrate interface.

\section{Tensile Tests}

The tensile tests enabled the determination of the mechanical properties and the identification of the influence of the minor Ga additions on these values. In order to execute the tensile tests, specimens were extracted from the ingots produced by using a graphite mold; and prepared according to specifications given in the ASTM E8/E8M-16a Standard. The applied strain rate was about $3 \times 10^{3} \mathrm{~s}^{-1}$, using a 5500R Instron machine.

\section{RESULTS AND DISCUSSION}

\section{Thermodynamics and As-Solidified Microstructures}

Figure 2 depicts the temperature decrease with respect to time during the slow cooling experiments. Four cooling curves can be seen. The highest attained cooling rate was, approximately, $0.02^{\circ} \mathrm{C} / \mathrm{s}$, which indicates that all the samples achieved near equilibrium conditions. The slope changes at $136^{\circ} \mathrm{C}$ could be attributed to the well-known Sn-Bi binary eutectic reaction. ${ }^{14}$ From the Gibbs rule concept, the addition of $\mathrm{Ga}$ increases the number of degrees of freedom. ${ }^{24}$ Consequently, the $\mathrm{Sn}-\mathrm{Bi}$ eutectic reaction does not behave as an invariant reaction in the case of the examined ternary alloys. This explains why the temperature continues to reduce for these alloys after attaining $136^{\circ} \mathrm{C}$. Moreover, considering the plots regarding the $\mathrm{Sn}-40 \mathrm{wt} \% \mathrm{Bi}(-\mathrm{Ga})$ alloys at left in Fig. 2, it can be noticed that a primary phase was formed prior to the Sn-Bi binary eutectic reaction.

Equilibrium and Scheil-Gulliver (SG) calculations were carried out using the TCSLD3 ThermoCalc database, in an effort to address the formed phases. Figures 3 and 4 show these calculations for all the evaluated alloys. For the Sn- 40 wt.\%Bi alloy, the primary phase formed is the tin-rich phase with a body-centered tetragonal lattice, which is expected to occur at $165^{\circ} \mathrm{C}$. This value could be considered reasonable with respect to the experimentally obtained $170^{\circ} \mathrm{C}$ (see Fig. 2).

Figure 5a shows the microstructures of the Sn40wt.\%Bi alloy obtained using optical microscopy. From these images, it can be easily noted that the microstructure is composed by a Sn-rich dendritic matrix with an interdendritic region having a $\mathrm{Sn}-\mathrm{Bi}$ irregular complex eutectic. Furthermore, small Birich precipitates could be found inside the Sn-rich dendrites. Silva et al. ${ }^{15}$ established that such precipitates can be generally classified into two morphologies, for instance: spheroid and ellipsoid. This is explained by the induced precipitation within the Sn-rich matrix as a consequence of the Bi solubility inside the $\mathrm{Sn}$ lattice, which is reduced due to temperature drop as a function of time.

In the case of the Sn-40wt.\%Bi-2wt.\%Ga alloy, a significant difference in the equilibrium (Fig. 3b) and Scheil-Gulliver-SG (Fig. 4b) calculations can be noted. Figure $5 \mathrm{~b}$ shows the microstructure features obtained using optical microscopy. A closer look at the equilibrium calculations suggests that the liquid phase would dissipate at, approximately, $80^{\circ} \mathrm{C}$. On the other hand, the SG calculations demonstrated that the solidification may cease only for temperatures around $15^{\circ} \mathrm{C}$. This difference can
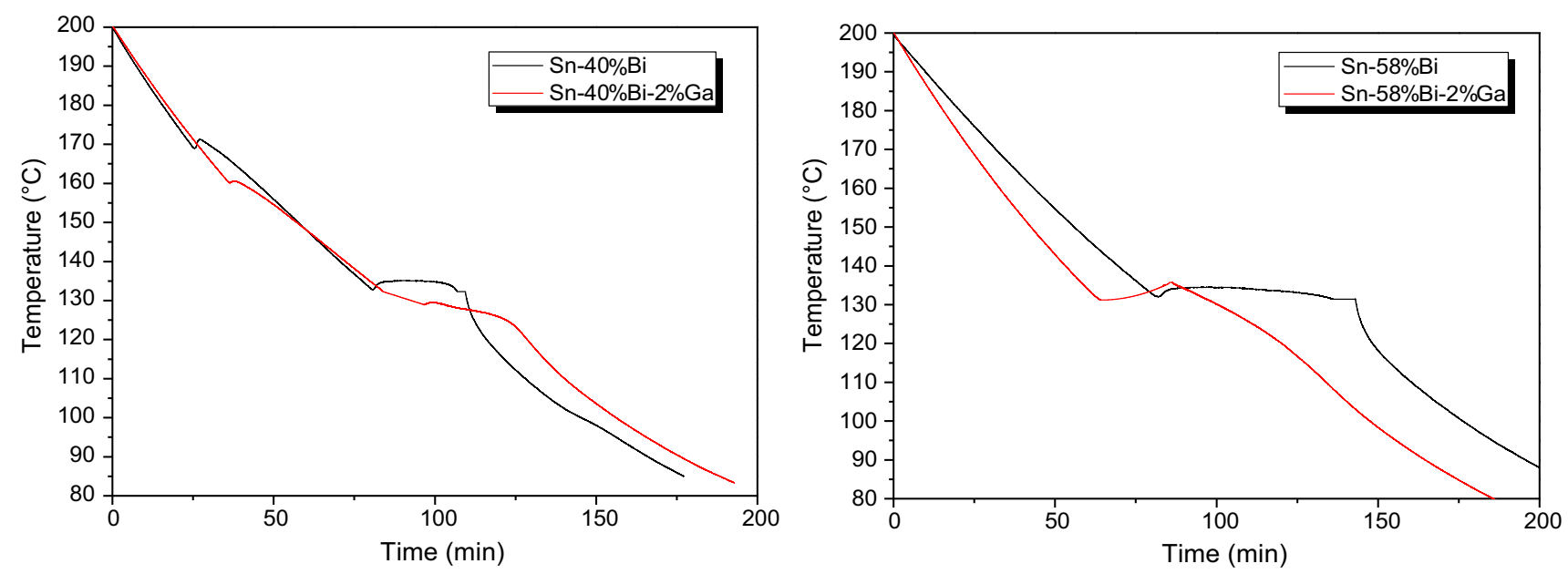

Fig. 2. Temperature versus time plots obtained from the slow-cooling experiments with the tested $\mathrm{Sn}-\mathrm{Bi}$ and $\mathrm{Sn}-\mathrm{Bi}-\mathrm{Ga}$ alloys. 

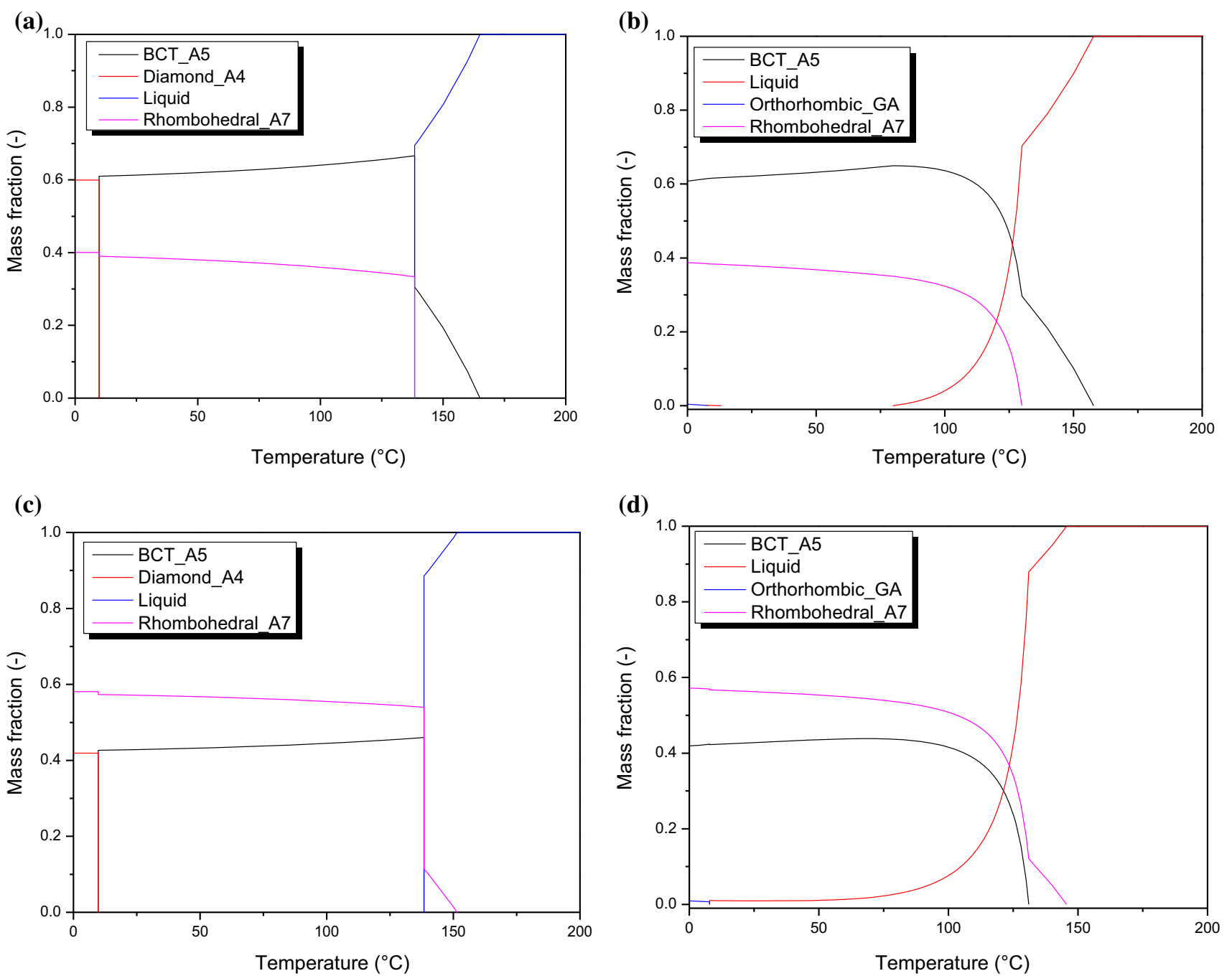

Fig. 3. Equilibrium calculations performed for the Sn-40wt.\%Bi (a), Sn-40wt.\%Bi-2wt.\%Ga (b), Sn-58wt.\%Bi (c) and Sn-58wt.\%Bi-2wt.\%Ga (d) alloys.

be related to the increase in the Ga-amount in the liquid-phase with the progress of solidification, as it is expected by applying the Scheil-Gulliver model.

The major consequence of such difference showed in the calculations could be related to the $\mathrm{Ga}$ distribution on the microstructure. Considering the equilibrium results, at the end of solidification, $\mathrm{Ga}$ is expected to appear in solution with the Sn-rich matrix as a substitutional impurity in the Snlattice. In contrast, the SG model suggests that this element would be located, preferentially, at the interdendritic region. On the basis of the evidence currently available in Fig. $5 \mathrm{~b}$, it seems fair to suggest that a condition closer to the equilibrium was attained during the slow cooling experiments, as only a minor fraction of pores occupied by $\mathrm{Ga}$ could be found on the Sn-dendrites/Bi-lamellae eutectic boundaries, indicating the preferential locations of these Ga-rich liquid phases.

Figures $3 c$ and $4 c$ depict the Thermo-Calc equilibrium and SG calculations for the Sn-58 wt.\%Bi alloy, respectively; whereas Fig. 5c shows the optical microscopy images of the related microstructure. Similarly, Thermo-Calc calculations and microstructures for the Sn-58wt.\%Bi-2wt.\%Ga alloy are shown in Figs. 3d and 4d. Regarding the occurrence of Ga-pores in the Sn-58wt.\%Bi2 wt.\%Ga alloy (Fig. 5d), a similar behavior as observed for the Sn-40wt.\%Bi-2wt.\%Ga alloy was demonstrated. In fact, even bigger porosities could be found in this case.

The investigated alloys appear to behave close to equilibrium solidification conditions. Therefore, it starts the formation of the primary Sn-rich phase, with redistribution of the Ga throughout the liquid and the Sn-rich phase. However, when the Sn-Bi eutectic starts to form, as the Bi-rich phase has no Ga-solubility (see Fig. 6), the Sn-rich phase region on the vicinity of the Sn-rich/Bi-rich phases boundaries significantly increases its Ga-content. As this happens at a low temperature $\left(136^{\circ} \mathrm{C}\right)$, in which substitutional elements do not have an important 
(a)

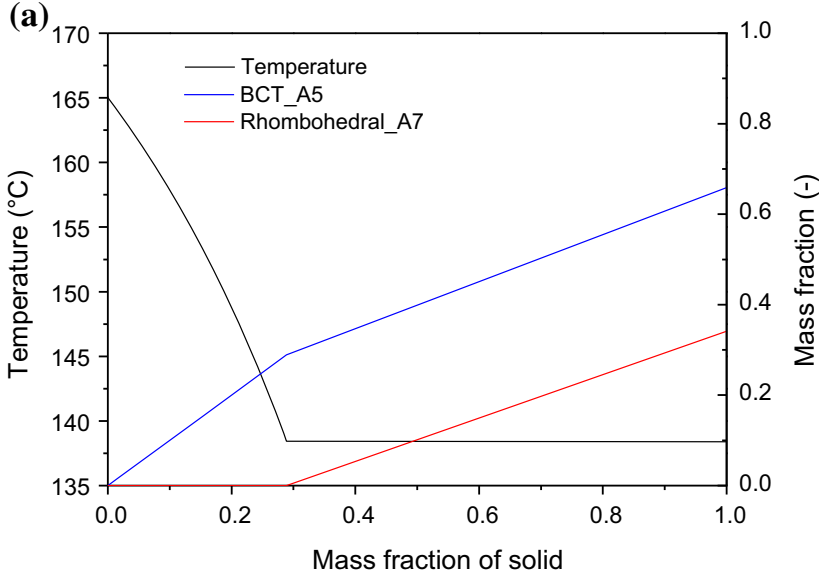

(c)

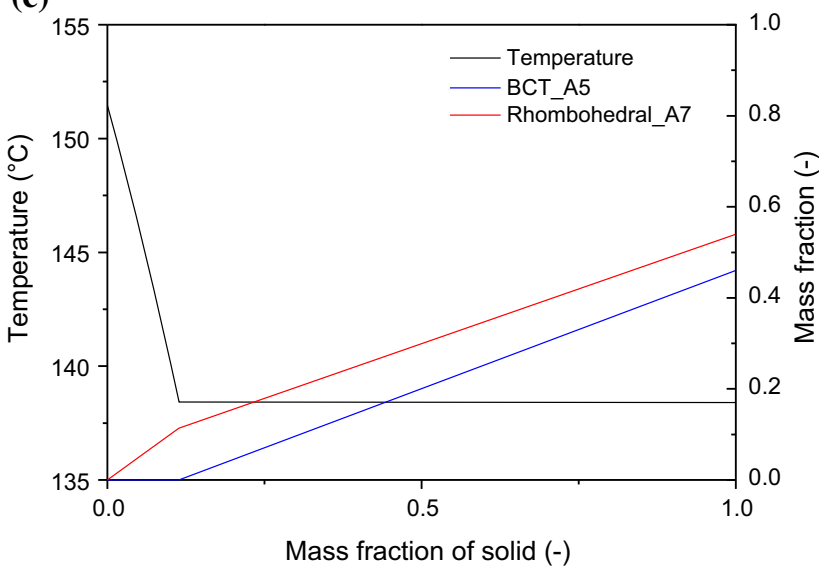

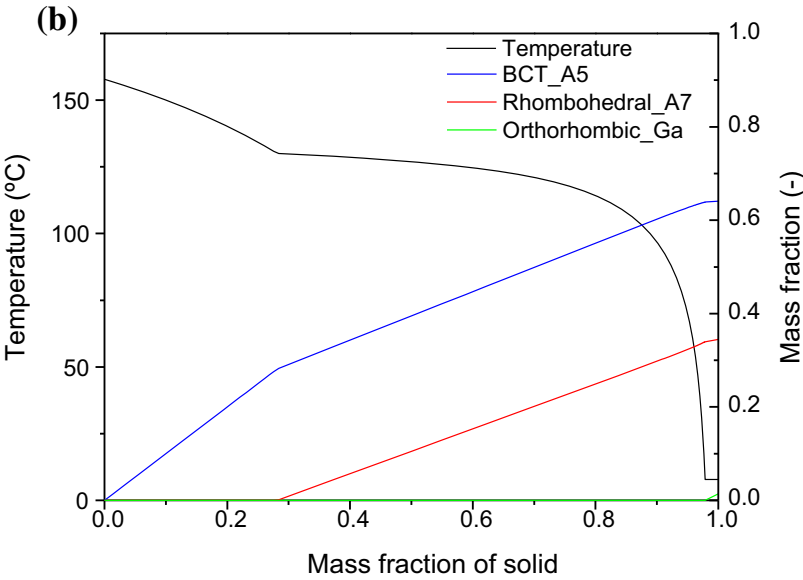

(d)

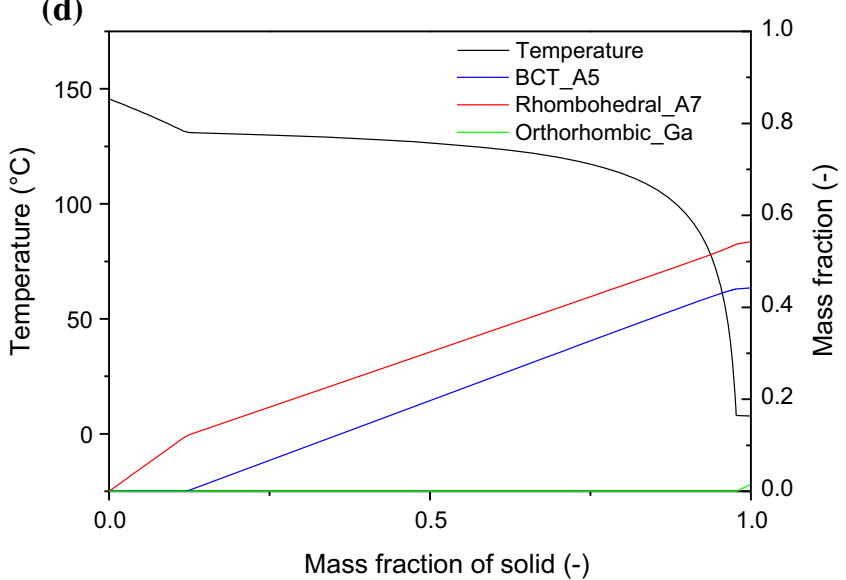

Fig. 4. Scheil-Gulliver calculations performed for the Sn-40wt.\%Bi (a), Sn-40wt.\%Bi-2wt.\%Ga (b), Sn-58wt.\%Bi (c) and Sn-58wt.\%Bi-2wt.\%Ga (d) alloys.

diffusion coefficient, the available time appears to be not enough to Ga to be redistributed throughout the Sn-rich phase. Therefore, a Ga-rich liquid phase forms preferentially onto the $\mathrm{Sn}$-rich/Sn-Bi eutectic boundaries.

The aforementioned mechanism could also explain why the Sn-58wt.\%Bi-2wt.\%Ga alloy was characterized by even bigger Ga-pores in size related to the Ga liquid phase. As there is a lower proportion of Sn-rich phase as compared to the Sn40wt.\%Bi-2wt.\%Ga, for the same Ga-content, the liquid became even richer with respect to the $\mathrm{Ga}$. In fact, this is supported by the equilibrium calculations showed in Fig. 6. The major difference with regard to these alloys is that a liquid phase in the Ga-containing Sn-58 wt.\%Bi alloy would be stable in equilibrium conditions, at the room temperature, due to its lower Sn-content. Under such conditions, $\mathrm{Ga}$ should not be found only within the Sn-rich phase, but also within the interdendritic region. However, the lower temperatures of transformation may induce lower diffusivity of $\mathrm{Ga}$ in the liquid ahead of the solidification front, avoiding the growth of Ga-liquid pores deeply inside the interdendritic areas in the present results.
Two other findings deserve to be highlighted. Firstly, Thermo-Calc calculations suggest that the primary phase in both Sn-58wt.\%Bi and the Sn58 wt.\%Bi-2wt.\%Ga alloys should be the Bi-rich phase with a rhombohedral lattice. However, it was noticed, for both cases, that a Sn-rich phase was in fact formed as the primary phase. It appears that the TCSLD3's database for the Sn-Bi system may not reproduce the exact good value for the $\mathrm{Sn}-\mathrm{Bi}$ eutectic reaction. Secondly, Ga appears to modify the Sn-rich primary phase morphology. This is possibly noted when the Sn-rich dendritic morphology in the $\mathrm{Sn}-58 \mathrm{wt} . \% \mathrm{Bi}$ alloy is compared to the faceted one found in the Sn-58wt.\%Bi-2wt.\%Ga alloy, as can be seen in details in Fig. 7.

\section{Wettability, Interfacial Reactions, and IMC Growth}

The temperatures used as the plateau temperature during wettability tests, the average contact angle $\left(\theta_{\mathrm{E}}\right)$ at the end of the process and the spreading area obtained in the wettability experiments for each of the studied chemistries are shown in Table I. Ga additions seem to have increased the average contact angle. The same understanding can 

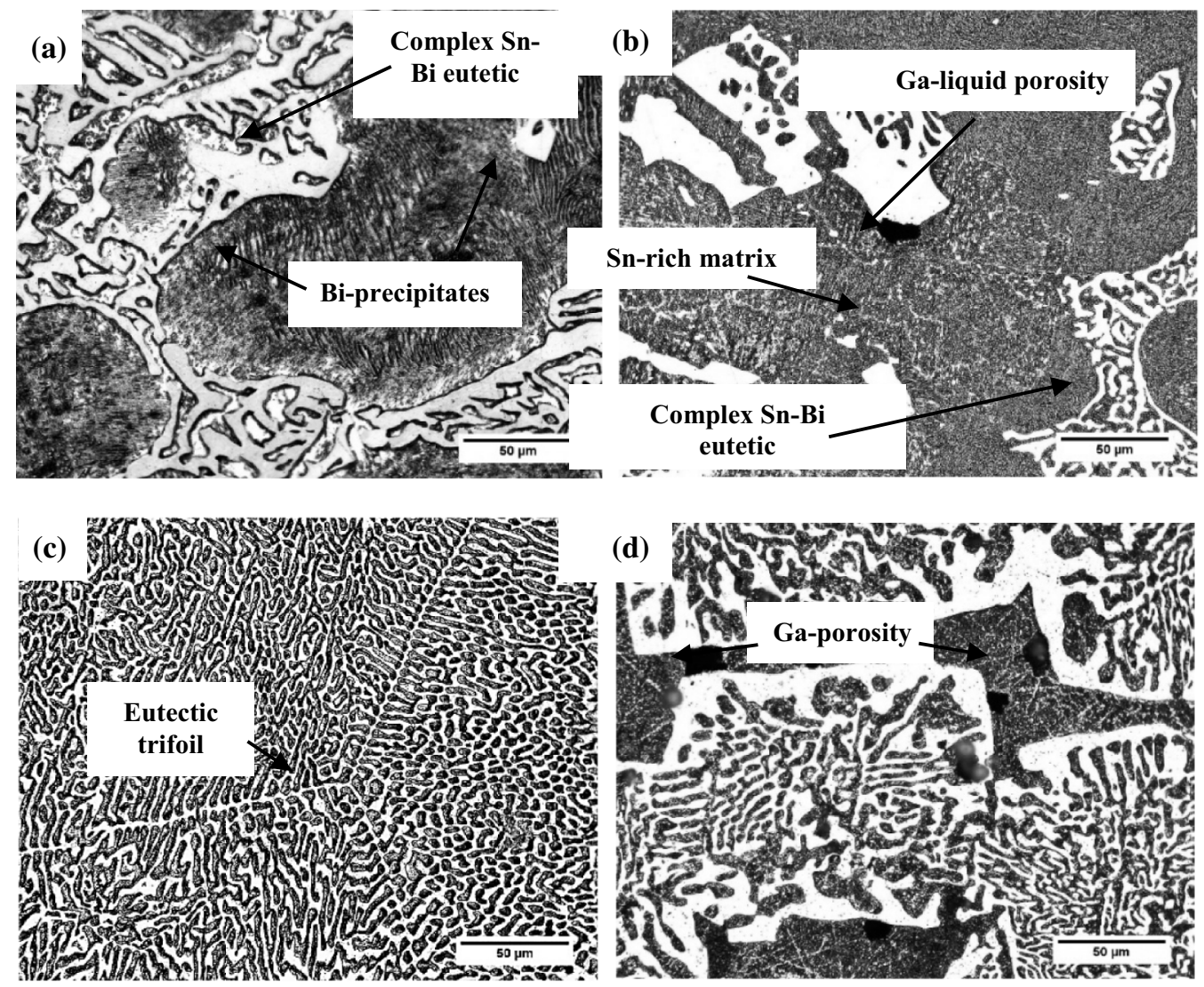

Fig. 5. Optical microstructures after slow-cooling solidification of the Sn-40wt.\%Bi (a), Sn-40wt.\%Bi-2wt.\%Ga (b), Sn-58wt.\%Bi (c) and Sn58wt.\%Bi-2wt.\%Ga (d) alloys.
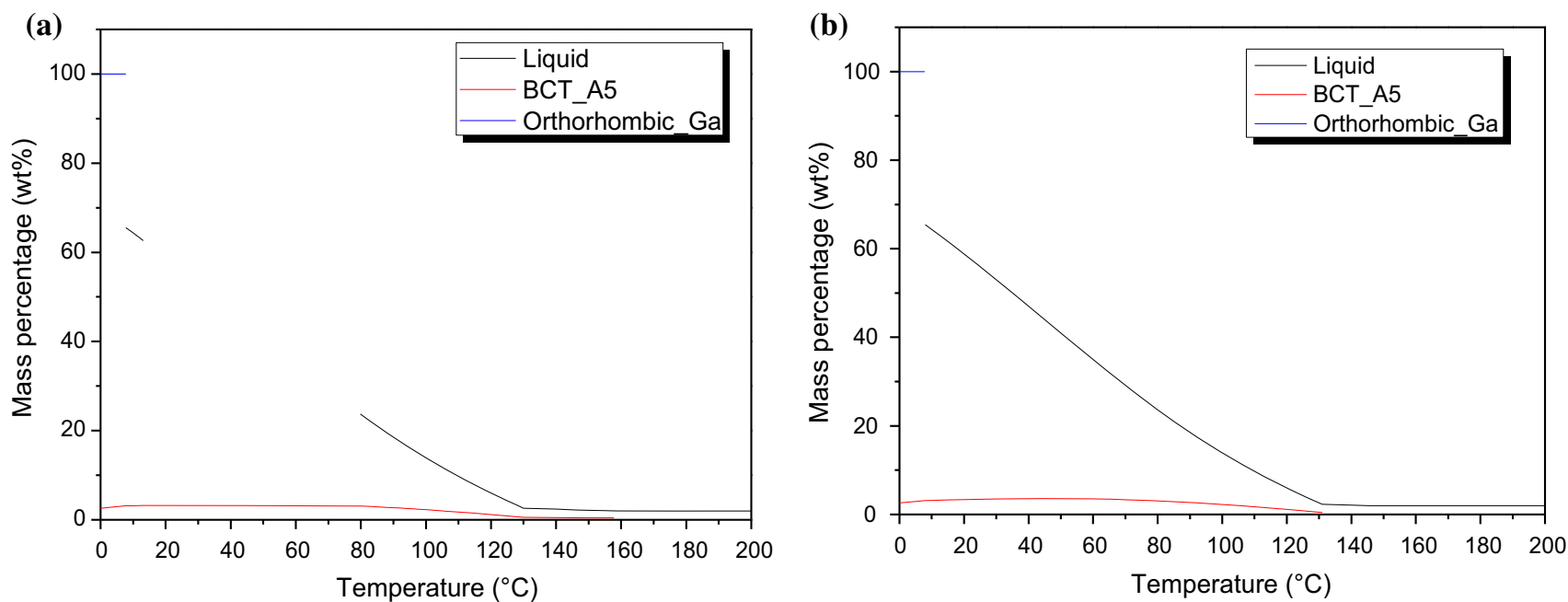

Fig. 6. Thermo-Calc calculations of the amount of Ga-containing phases under equilibrium conditions, using the TCSLD3 database of the Thermo-Calc software for: Sn-40wt.\%Bi-2wt.\%Ga (a) and Sn-58wt.\%Bi-2wt.\%Ga (b) alloys.

be established from the spreading results. Anyway, the results are in agreement with prior experiments found in the literature. ${ }^{25}$

Figure $8 \mathrm{a}$ shows the $\mathrm{Sn}-40 \mathrm{wt} . \% \mathrm{Bi} / \mathrm{Cu}$ substrate SEM microstructures obtained after the soldering process, as well as for $120 \mathrm{~h}$ (Fig. 8b) and for $360 \mathrm{~h}$
(Fig. 8c) of isothermal heat-treatment at $100^{\circ} \mathrm{C}$. The microstructure shown in Fig. 8a can be described as a Sn-rich dendritic matrix with an interdendritic region composed by the $\mathrm{Sn}-\mathrm{Bi}$ eutectic mixture. Considering that the $\mathrm{Sn}-\mathrm{Bi}$ eutectic is the last phase to form, it can be perceived that the region closer to 

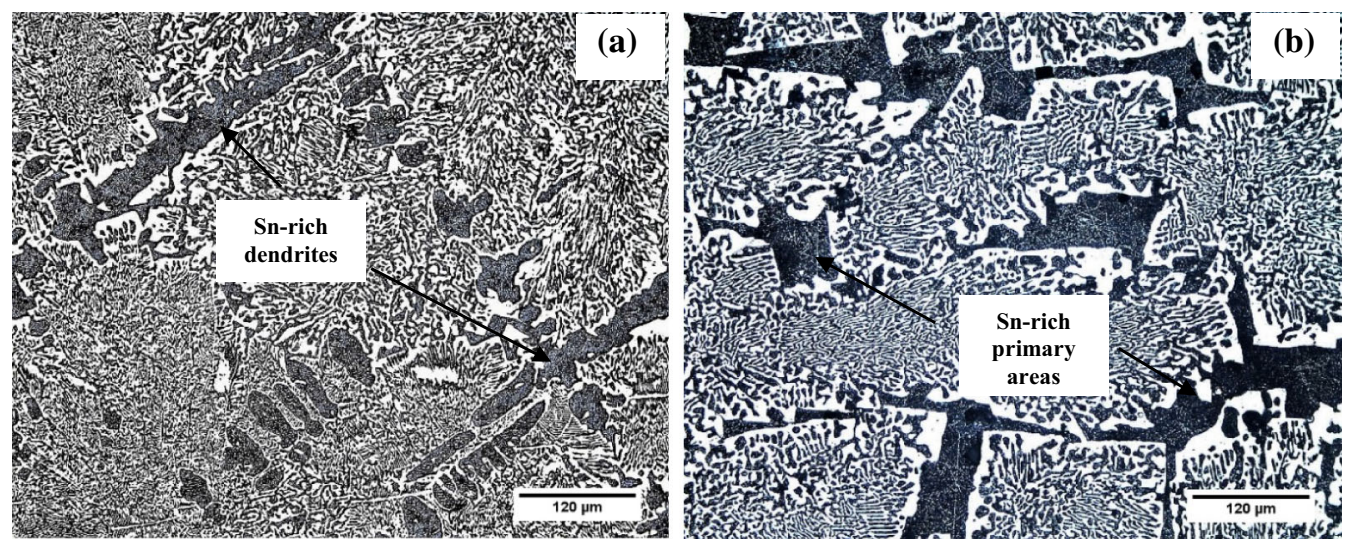

Fig. 7. Optical microstructures emphasizing the formed morphologies of the primary Sn-rich phase in the Sn-58wt.\%Bi (a) and $\mathrm{Sn}-58 \mathrm{wt} . \% \mathrm{Bi}-$ 2wt.\%Ga (b) alloys.

Table I. Tested temperature, average contact angle and spreading area \% for all evaluated Sn-Bi(-Ga) alloys in Cu substrate

\begin{tabular}{|c|c|c|c|c|}
\hline Alloys & Sn-40wt.\%Bi & Sn-40wt.\%Bi-2wt.\%Ga & Sn-58wt.\%Bi & Sn-58wt.\%Bi-2wt.\%Ga \\
\hline mperature $\left({ }^{\circ} \mathrm{C}\right)$ & $205^{\circ} \mathrm{C}$ & $193^{\circ} \mathrm{C}$ & $162^{\circ} \mathrm{C}$ & $162^{\circ} \mathrm{C}$ \\
\hline Contact angle, $\theta_{\mathrm{E}}\left({ }^{\circ}\right)$ & $21^{\circ} \pm 5^{\circ}$ & $33^{\circ} \pm 6^{\circ}$ & $21^{\circ} \pm 2^{\circ}$ & $46^{\circ} \pm 10^{\circ}$ \\
\hline Spreading area (\%) & $1.47 \pm 0.07$ & $1.1 \pm 0.1$ & $1.29 \pm 0.06$ & $0.9 \pm 0.2$ \\
\hline
\end{tabular}
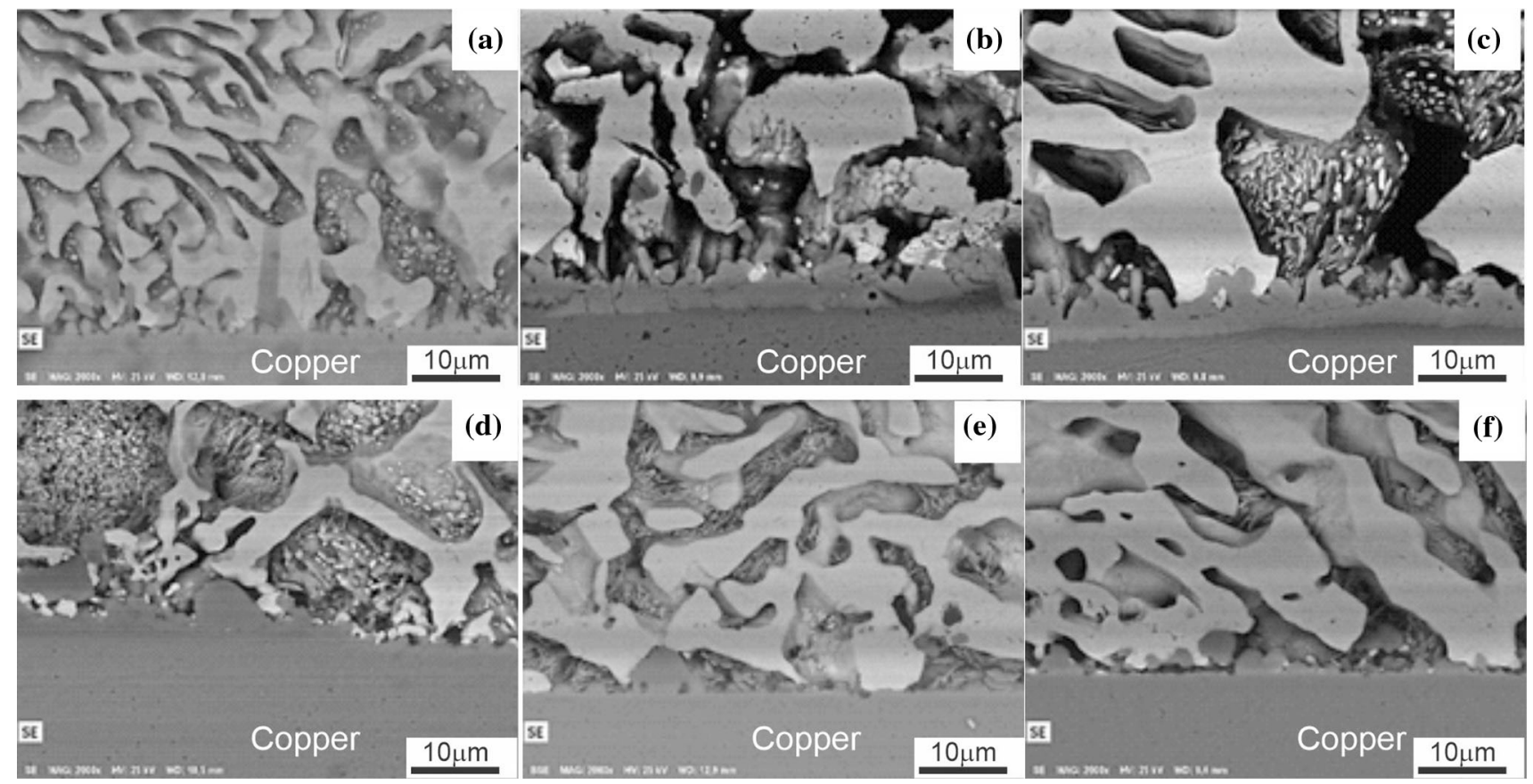

Fig. 8. Sn-40wt.\%Bi/Cu substrate microstructures obtained after the soldering step (a), as well as after $120 \mathrm{~h}$ (b) and $360 \mathrm{~h}$ (c) of isothermal heat-treatment at $100^{\circ} \mathrm{C}$. Similarly, Sn-40wt.\%Bi-2wt.\%Ga/Cu substrate microstructures found after the soldering step (d), as well as after $120 \mathrm{~h}$ (e) and $360 \mathrm{~h}(\mathrm{f})$ of aging.

the $\mathrm{Cu}$ surface (at the bottom of Fig. 8a) was, possibly, the last region to solidify. In fact, this seems like a feasible possibility, as the argon gas of the purging atmosphere is constantly renewed, thereby extracting heat by the droplet/gas surface. Due to its bigger volume as compared to the alloy volume itself, as well as the longer preset heating times, the $\mathrm{Cu}$ substrate may act as a heat 
accumulator, with respect to the molten solder, which could explain this observation.

Concerning the isothermal heat-treatments effects, the Sn-rich dendritic morphology changed to a globular one. In the same way, the eutectic lamellae did also show a modification in the direction of a coarser morphology. With regard to the IMC layer, several energy dispersive spectroscopy (EDS) analyses were performed, in order to better evaluate the elements distributed throughout the interface. The images are shown in Fig. 9a; which shows the interface right after the soldering, as well as after $360 \mathrm{~h}$ (Fig. 9b) of heat-treatment, respectively. In a similar manner, the results for the Sn40wt.\%Bi-2wt.\%Ga are shown in Fig. 10. Furthermore, line scans, which were made throughout the interface in order to better evaluate the elements dispersal and diffusion profiles, are shown in Fig. 11, where (a, b and c) show the results for the Sn-40wt.\%Bi and (d, e and f) for the Sn-40wt.\%Bi2wt.\%Ga.

As the chemical solution used to reveal the microstructure preferentially attacks the Sn-rich phase, the EDS analysis probably highlighted even more the Sn presence at the IMC layer. Moreover, it can be noticed that the IMC composition seems to be that of the $\mathrm{Cu}_{6} \mathrm{Sn}_{5}$, although the results show a higher Sn-content. This difference could be related to the well-known bulk effect on the EDS quantification.

On the other hand, it was not possible to identify the $\mathrm{Cu}_{3} \mathrm{Sn}$ cited by other authors. ${ }^{13}$ In this case, the data appears to suggest a transitional region created by diffusion from $\mathrm{Cu}$ towards the IMC layer. Although this may be acceptable, a potential $\mathrm{Cu}_{3} \mathrm{Sn}$ layer might be so thin that this result could also be related to the bulk effects in the EDS analysis.

Interestingly, non-expected needle-like phases were perceived not only starting from the interface, but also in regions relatively far from it, as can be seen in Fig. 12. These phases are in fact $\mathrm{Cu}_{6} \mathrm{Sn}_{5}$ that did form after, due to the Cu-content increase in the open liquid. On the basis of the evidence currently available, it seems fair to suggest that the first ones were formed by heterogeneous nucleation in the IMC layer, as the temperature decreased. Concerning the second ones, several reasons could be underlined to understand their formation. The main enlightenment could be related to homogeneous nucleation after a temperature decrease, or growth of an IMC particle that detached from the IMC layer due to convective currents within the liquid.

The data yielded by EDS analysis of the Sn40wt.\%Bi-2wt.\%Ga alloy provide convincing evidence that Ga indeed suppressed the CuSn IMC layer formation, as it has already been demonstrated. ${ }^{13}$ It is worth noting that the CuSn IMC layer suppression came out of Ga expended in the formation of a Ga-rich IMC layer. It seems reasonable to suggest that the CuGa IMC formed was the $\mathrm{Cu}_{9} \mathrm{Ga}_{4}$. Moreover, similarly to Lin et al. ${ }^{13}$ rounded $\mathrm{Cu}_{9} \mathrm{Ga}_{4}$-were found starting to grow from the interface. This indicates that the CuGa IMC layer did not effectively suppress the $\mathrm{Cu}$ dissolution into the bulk, although the change in the morphology may indicate a better mechanical resistance of the reaction layer, as compared to that of the $\mathrm{CuSn}$ needle-like IMC found in the Sn-40wt.\%Bi alloy samples.

Figure 13 depicts the joint microstructure evolution of the Sn-58wt.\%Bi and Sn-58wt.\%Bi-2wt.\%Ga alloys as a function of the aging time. In addition, Figs. 14 and 15 show the EDS mapping analyses of the reaction film formed right after the soldering, along with the images of the joint after $120 \mathrm{~h}$ and $360 \mathrm{~h}$ of heat-treatment In addition, as in the previous cases, line scans were also carried out across the interface as can be seen in Fig. 16.
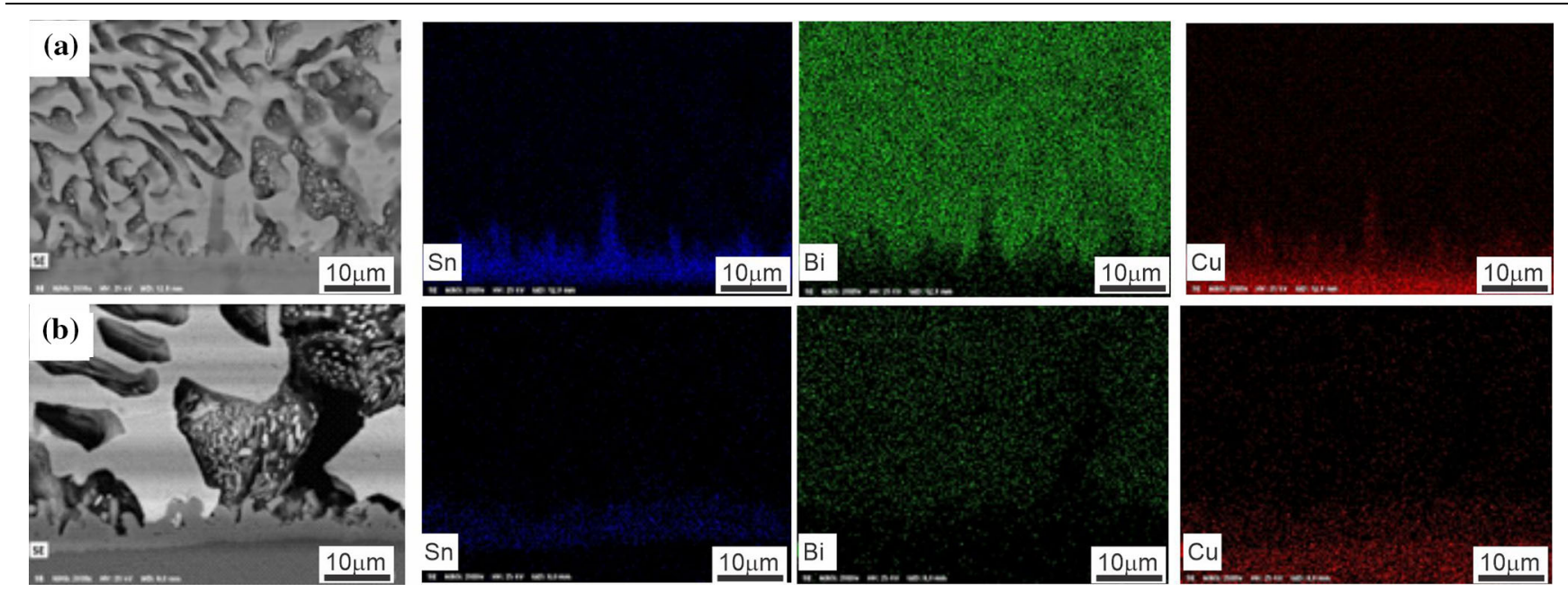

Fig. 9. Elements distribution throughout the $\mathrm{Sn}-40 \mathrm{wt} . \% \mathrm{Bi} / \mathrm{Cu}$ substrate interface after the wettability experiment (a), as well as after $360 \mathrm{~h}$ of heat-treatment at $100^{\circ} \mathrm{C}(\mathrm{b})$. 

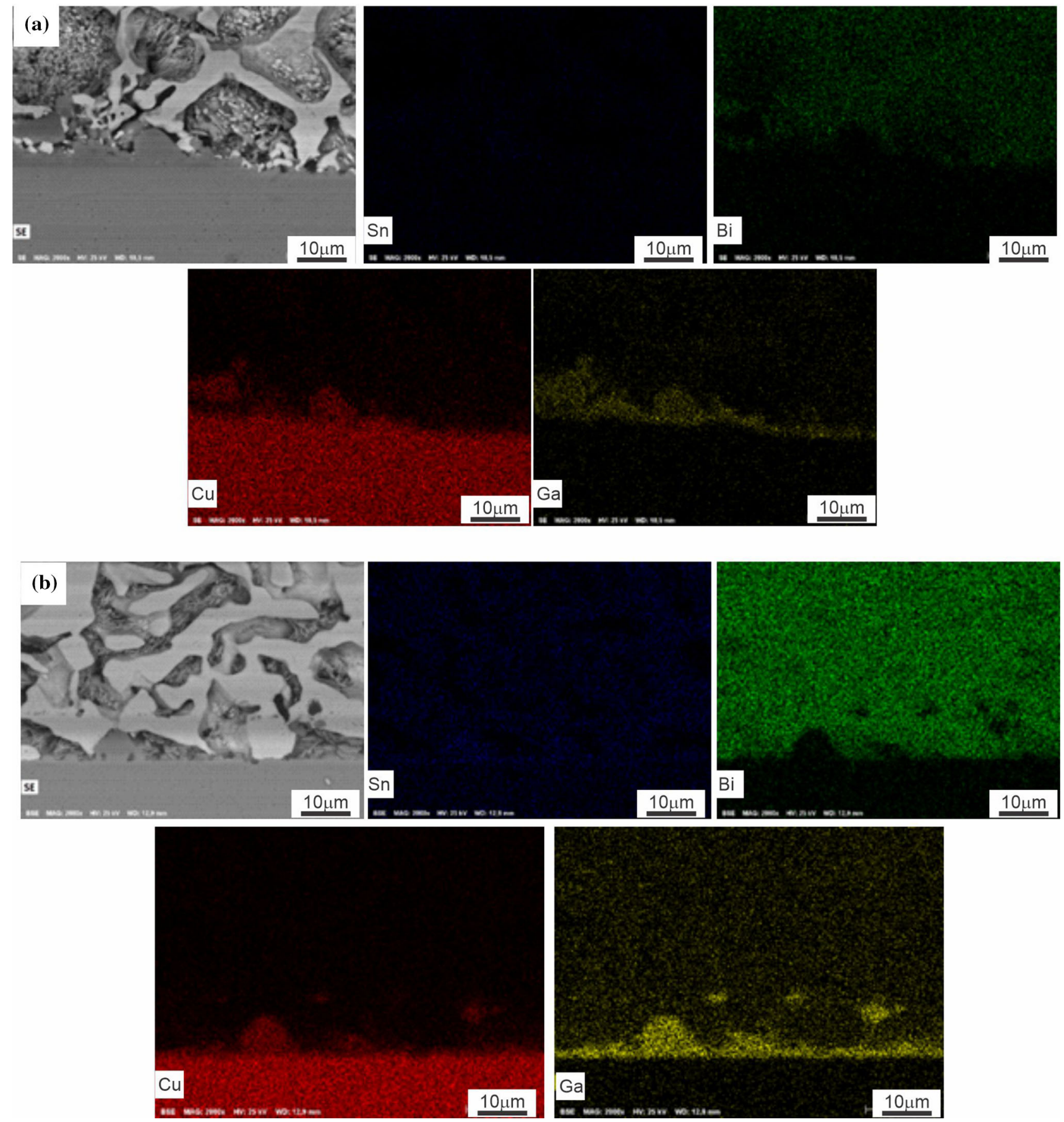

Fig. 10. Elements distribution across the $\mathrm{Sn}-40 \mathrm{wt} . \% \mathrm{Bi}-2 \mathrm{wt} . \% \mathrm{Ga} / \mathrm{Cu}$ substrate interface after the wettability experiment (a), as well as after $120 \mathrm{~h}$ of heat-treatment at $100^{\circ} \mathrm{C}(\mathrm{b})$.

Likewise, the data yielded by these EDS analyses provide strong evidence of the CuSn IMC layer formation at the $\mathrm{Sn}-\mathrm{Bi} / \mathrm{Cu}$ interface, as expected. Also, small IMC incrustations could be remarked at the IMC layer, even though they were less perceivable after the samples being heat-treated, which was not exactly the case with respect to the Sn40wt.\%Bi alloy samples. Finally, none CuSn IMC was found away from the interface. This fact could be related to a lower $\mathrm{Cu}$-solubility in the liquid alloy composition during solidification of the Sn58 wt.\% Bi alloy against the $\mathrm{Cu}$ substrate. It is mainly explained by the decrease in the alloy Sncontent as compared to the Sn-40wt.\%Bi alloy.

Concerning the formed reaction layer, the $\mathrm{CuSn}$ IMC appeared to be richer in Sn than expected. Similarly, a diffusion region was formed with respect to the $\mathrm{Sn}$ and $\mathrm{Cu}$ concentrations along the 

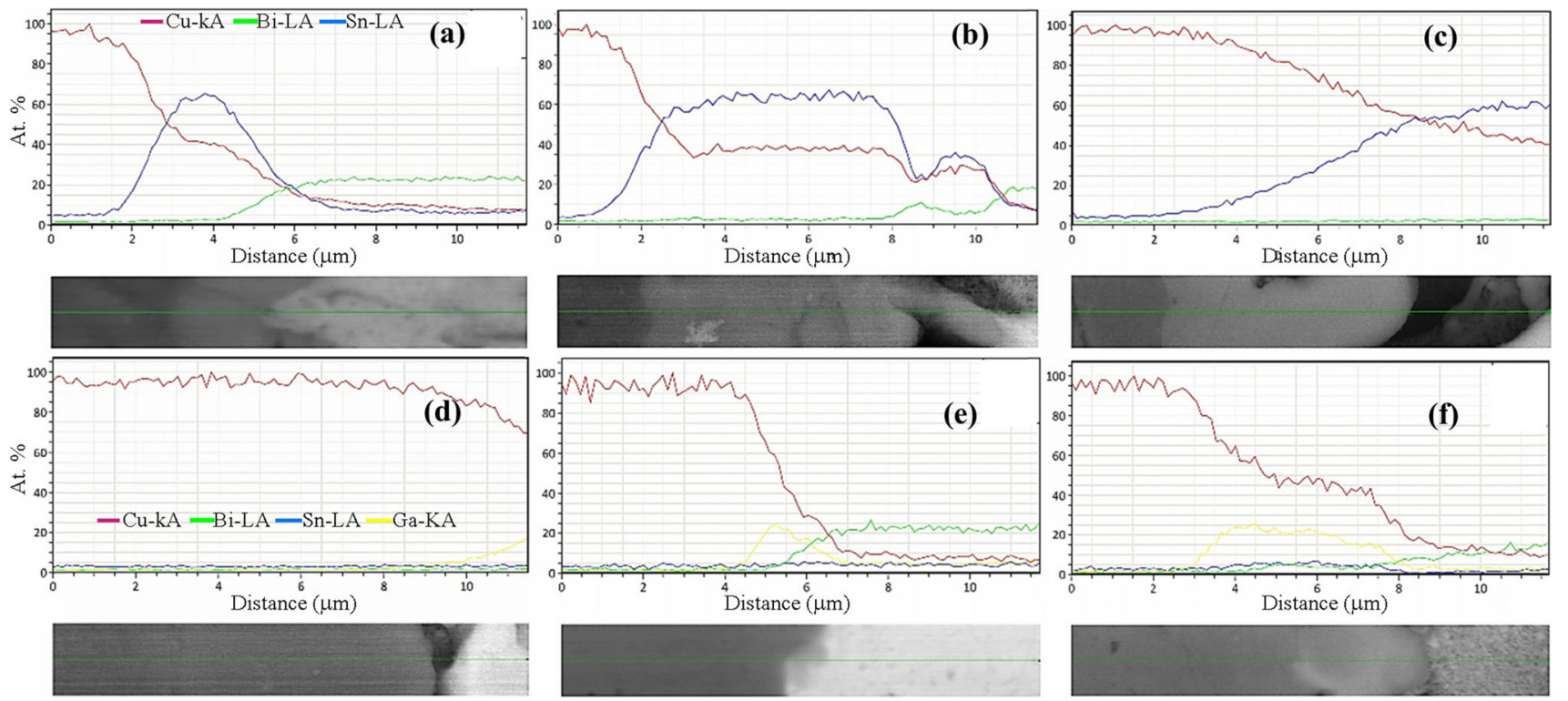

Fig. 11. Line scans across the Sn-40wt.\%Bi/Cu substrate interface after the soldering (a), as well as for $120 \mathrm{~h}$ (b) and $360 \mathrm{~h}$ (c) of isothermal heat-treatment at $100^{\circ} \mathrm{C}$. Similar results are disposed in the same manner for the $\mathrm{Sn}-40 \mathrm{wt} . \% \mathrm{Bi}-2 \mathrm{wt} . \% \mathrm{Ga} / \mathrm{Cu}$ substrate sample (d-as soldered, e-for $120 \mathrm{~h}$, f-for $360 \mathrm{~h}$ ).

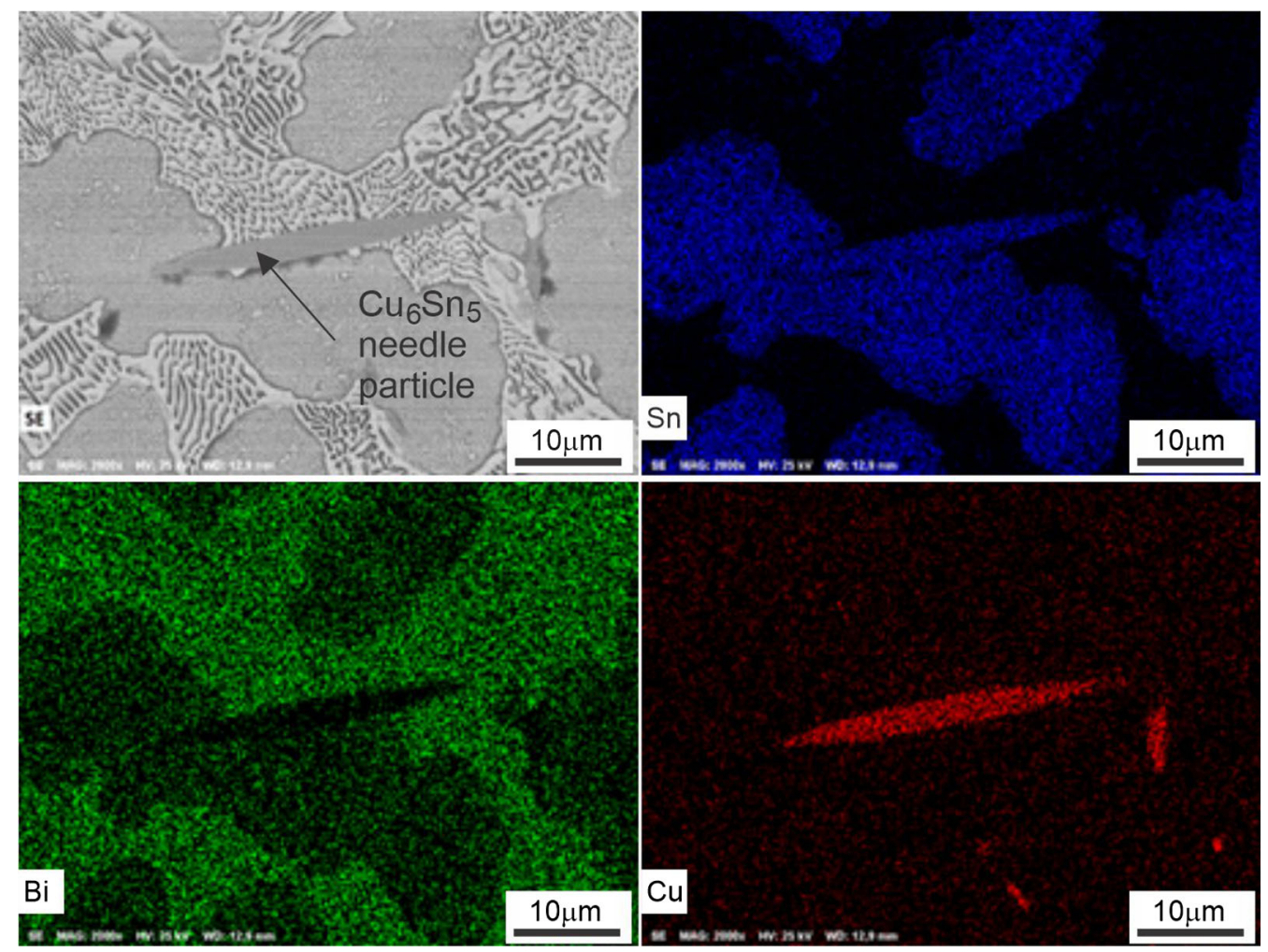

Fig. 12. Mapping of the elements across the Sn-40wt.\%Bi/Cu substrate interface after $360 \mathrm{~h}$ at $100^{\circ} \mathrm{C}$.

scan line analyzed. Both explanations presented for the case of the Sn-40wt.\%Bi alloy that may also be used to address such results.

Although primary Bi-rich particles were not detected in the previously shown microstructures of the Sn-58wt.\%Bi-2wt.\%Ga alloy under slow- cooling ("Thermodynamics and As-Solidified Microstructures" section), they were found in the as-soldered samples. In this case, the Ga-consumption may have shifted the remaining liquid towards the hyper-eutectic region of the Sn-Bi diagram. Moreover, such Bi-rich phases were found closer to 


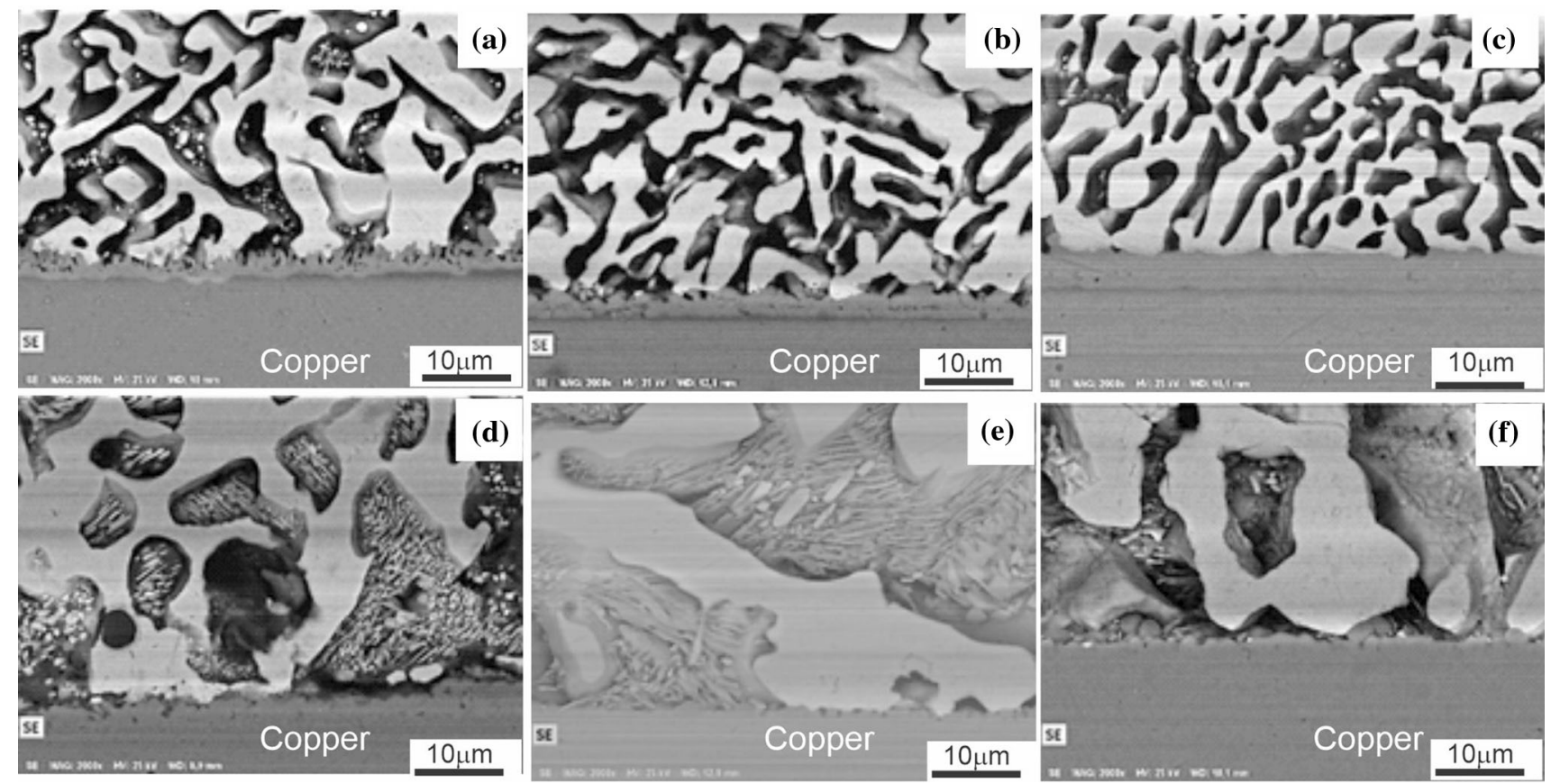

Fig. 13. Sn-58wt.\%Bi/Cu substrate secondary electrons SEM images obtained after the soldering step (a), as well as after $120 \mathrm{~h}$ (b) and $360 \mathrm{~h}$ (c) of isothermal heat-treatment at $100^{\circ} \mathrm{C}$. Similarly, Sn-58wt.\%Bi-2 wt.\%Ga/Cu substrate microstructures found after the soldering (d), as well as after $120 \mathrm{~h}(\mathrm{e})$ and $360 \mathrm{~h}(\mathrm{f})$ of aging.
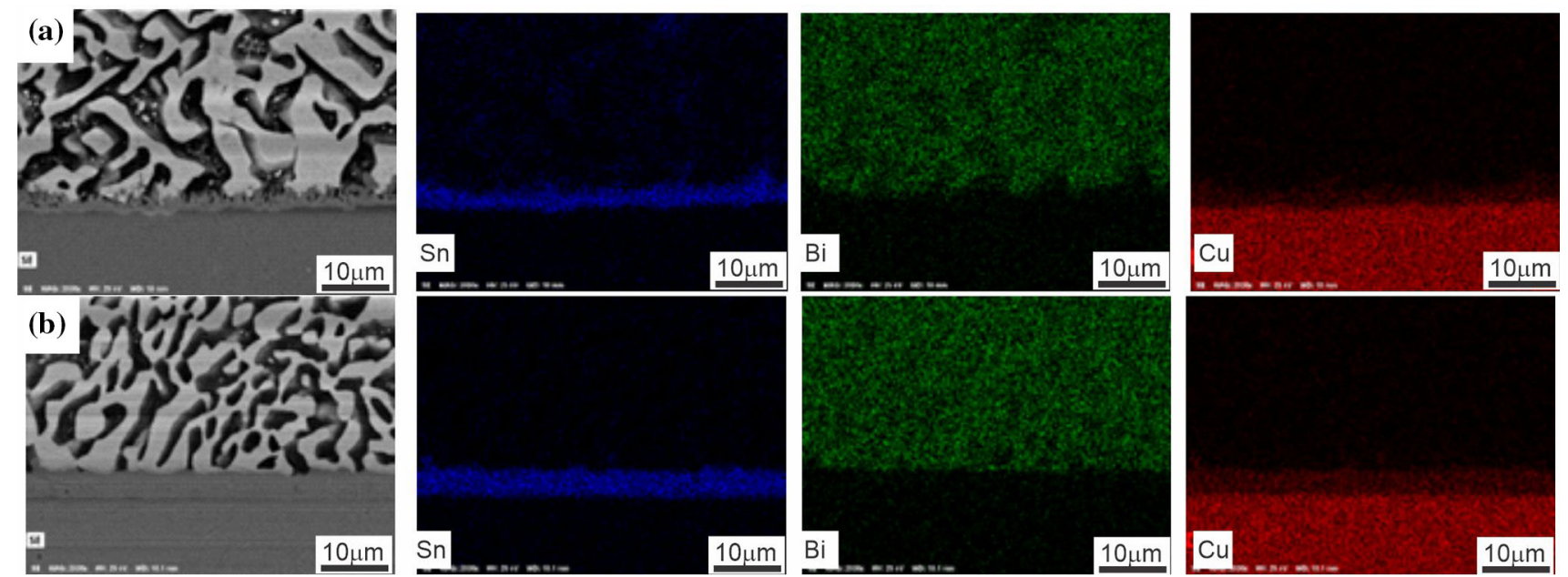

Fig. 14. Elements distribution throughout the $\mathrm{Sn}-58 \mathrm{wt} . \% \mathrm{Bi} / \mathrm{Cu}$ substrate interface obtained for the wettability experiment (a), and for $360 \mathrm{~h}$ of heat-treatment at $100^{\circ} \mathrm{C}(\mathrm{b})$.

the droplet surface in contact with argon gas, which also would indicate that this region is the first to experience nucleation of solid phases.

The heat-treated samples did show coarser lamellae, as well as the formation of the CuGa IMC layer, which became thicker with time.

The IMC layer thicknesses of the as-soldered and after $120 \mathrm{~h}$ heat-treated samples showed an intricate characteristic, since the layers were so thin that it was a very complicated task to differentiate them from the $\mathrm{Cu}$ substrate. However, the as-heattreated $360 \mathrm{~h}$ samples showed quite differentiable films. The measured thicknesses of these formed films for all evaluated alloys can be seen in Fig. 17. The Sn-40wt.\%Bi-2wt.\%Ga alloy layer was observed to be the thinnest one, whereas the Sn-58wt.\%Bi alloy was related to the worst results.

\section{Mechanical Behavior}

Figure 18 shows the comparison of the results of the first tested specimen for each of the Sn40wt.\%Bi(-2wt.\%Ga) and Sn-58wt.\%(-2wt.\%Ga) alloys. The results for the Sn-40wt.\%Bi(-2wt.\%Ga) alloys showed some correspondence, having an 

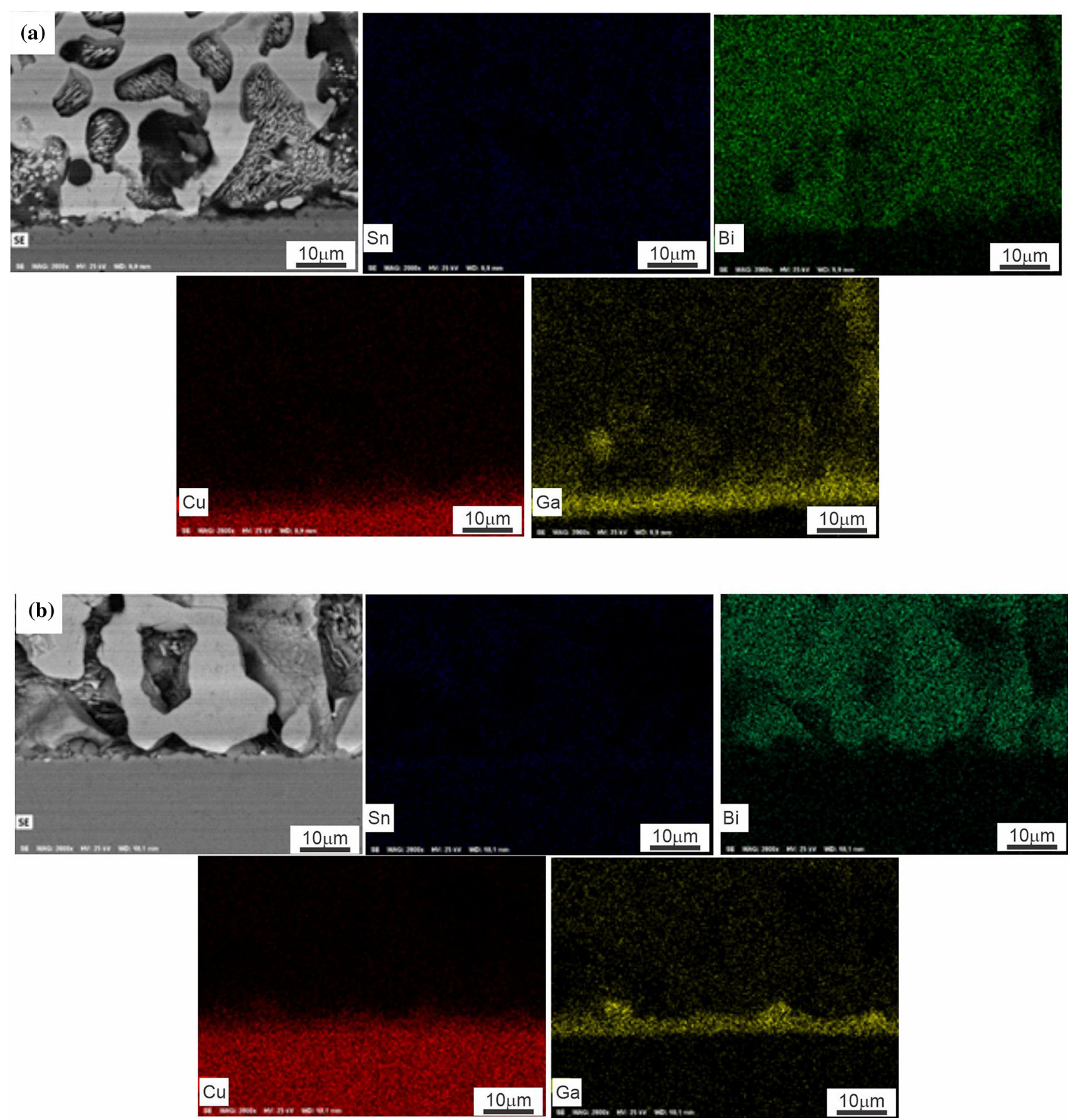

Fig. 15. Elements distribution throughout the Sn-58wt.\%Bi-2 wt.\%Ga/Cu substrate interface obtained for the wettability experiment (a), and for $360 \mathrm{~h}$ of heat-treatment at $100^{\circ} \mathrm{C}(\mathrm{b})$.

ultimate tensile strength (UTS) of, approximately, $77 \mathrm{MPa}$, with an average fracture strain of $28 \%$ for the alloy without $\mathrm{Ga}$. On the other hand, the Sn40wt.\%Bi-2wt.\%Ga alloy showed almost no plastic deformation, although its average UTS was quite close to that found for the Sn-40wt.\%Bi alloy.

Concerning the Sn-58wt.\%Bi alloy tensile parameters, a UTS of about $67 \mathrm{MPa}$ was attained, whereas an average strain-to-failure of $50 \%$ was achieved with some of the samples surpassing $65 \%$ of elongation-to-fracture. Despite that, it should be noticed that the Sn-58wt.\%Bi-2wt.\%Ga alloy samples showed elongation-to-fracture values lower than $0.4 \%$, characterizing an important brittle characteristic of the material.

At this point, the existence of a Ga-rich liquid phase had already been stressed enough. In fact, the Garich liquid phase regions are considered like cracks in the continuum solid mechanics. Therefore, to a certain extent, the Ga-additions introduce cracks in the bulk solders. As it is well known, these cracks reduce the critical stress necessary to start the 

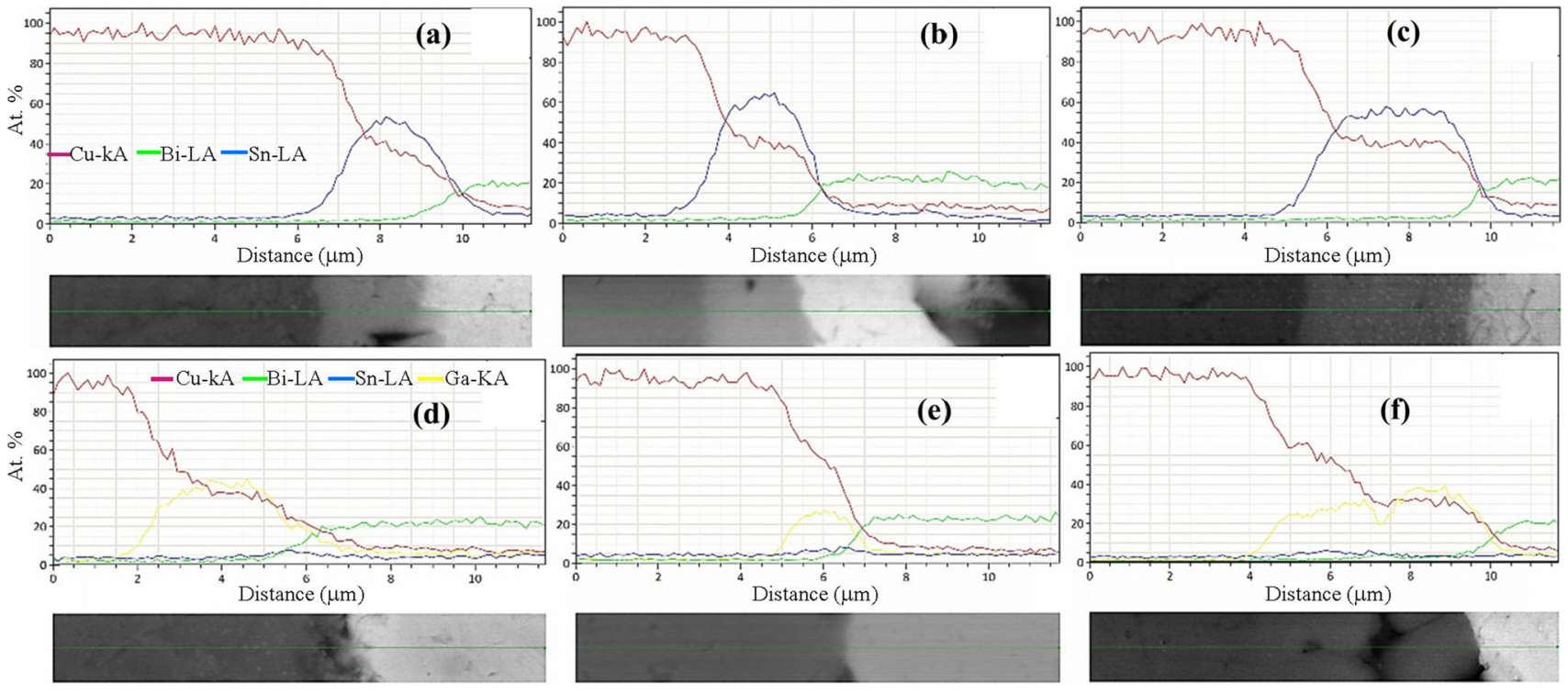

Fig. 16. Line scans across the $\mathrm{Sn}-58 \mathrm{wt} . \% \mathrm{Bi} / \mathrm{Cu}$ substrate interface after soldering (a), as well as after $120 \mathrm{~h}$ (b) and $360 \mathrm{~h}$ (c) of isothermal of heat-treatment at $100^{\circ} \mathrm{C}$. Similar results are arranged at the same manner for the $\mathrm{Sn}-58 \mathrm{wt} . \% \mathrm{Bi}-2 \mathrm{wt} . \% \mathrm{Ga} / \mathrm{Cu}$ substrate sample (d-as soldered, e-for 120 , f-for $360 \mathrm{~h}$ ).

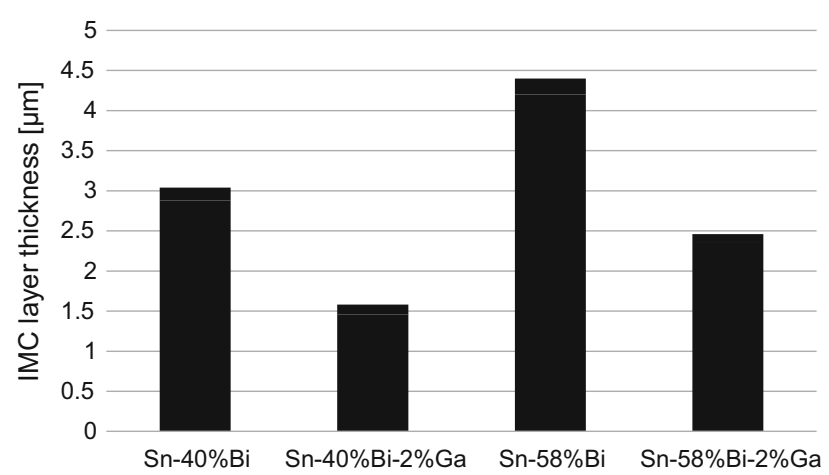

Fig. 17. IMC thicknesses for $360 \mathrm{~h}$ of heat-treatment of the $\mathrm{Sn}-\mathrm{Bi}$ (-Ga) alloys at $100^{\circ} \mathrm{C}$.

material fracture. This idea can also be perceived based in the $K_{\mathrm{IC}}$ formula, $K_{\mathrm{IC}}=Y \sigma_{\mathrm{c}} \sqrt{\pi a},{ }^{26}$ which can be considered the major theoretical premise behind the brittleness of the Ga-containing solders. The mentioned stress intensity factor $\left(K_{\mathrm{IC}}\right)$ describes the fracture toughness of materials under conditions of brittle fracture, where ' $a$ ' is the critical crack length in an infinite plate, ' $\sigma_{\mathrm{c}}$ ' is the applied stress and ' $Y$ ' is a parameter dependent on specimen and crack geometry.

\section{CONCLUSIONS}

Near-equilibrium conditions of solidification were attained with support of the proposed methodology. Cooling rates of about $0.02^{\circ} \mathrm{C} / \mathrm{s}$ allowed the microstructural investigation of the four tested TIM alloys in a comparative basis.

It was observed that the process starts with the formation of the primary Sn-rich phase with time to certain redistribution of $\mathrm{Ga}$ throughout the liquid and the Sn-rich phase. Next, the Sn-Bi eutectic starts to form. The Sn-rich phase region in the vicinity of the primary Sn-rich/Bi-lamellae boundaries increase its Ga-content, giving origin to the Ga-rich liquid phase to be formed. This is explained by both negligible Ga-solubility in the Bi-rich phase and a very low temperature related to the eutectic reaction, in which substitutional elements as Ga do not have an important diffusion coefficient.

The occurrence of Ga-pores following the proposed mechanism was observed in both Sn-40wt.\%Bi2wt.\%Ga and $\mathrm{Sn}-58 \mathrm{wt} . \% \mathrm{Bi}-2 \mathrm{wt} . \% \mathrm{Ga}$ alloys, but the later was characterized by larger Ga-pores in size. Furthermore, Ga modified the Sn-rich primary phase morphology, which transitioned from unfaceted to faceted Sn-rich dendrites. Ga additions induced the formation of a Ga-rich liquid phase, which significantly deteriorates the tensile properties, since the samples almost did not show any plastic deformation.

Considering the results obtained for the as-soldered conditions, the Ga additions increased the equilibrium contact angle and decreased the spreading area of the as-soldered $\mathrm{Sn}-\mathrm{Bi}$ chemistries in a $\mathrm{Cu}$ substrate. Also, it was detected the presence of $\mathrm{Cu}_{6} \mathrm{Sn}_{5}$ IMC throughout the solidified Sn-40wt.\%Bi alloy droplets (that is, away from the interface), which shows that a high quantity of $\mathrm{Cu}$ was dissolved and distributed in the molten alloy during the reflow process. Such a process was not observed in the Sn-58wt.\%Bi alloy samples. $\mathrm{Ga}$ additions effectively suppress the formation of the CuSn IMC by replacing it with a CuGa IMC layer, which is characterized by a less deleterious morphology growing from the $\mathrm{Cu}$ substrate.

The Sn-40wt.\%Bi-2wt.\%Ga alloy was found to be the composition characterized by the thinnest IMC 

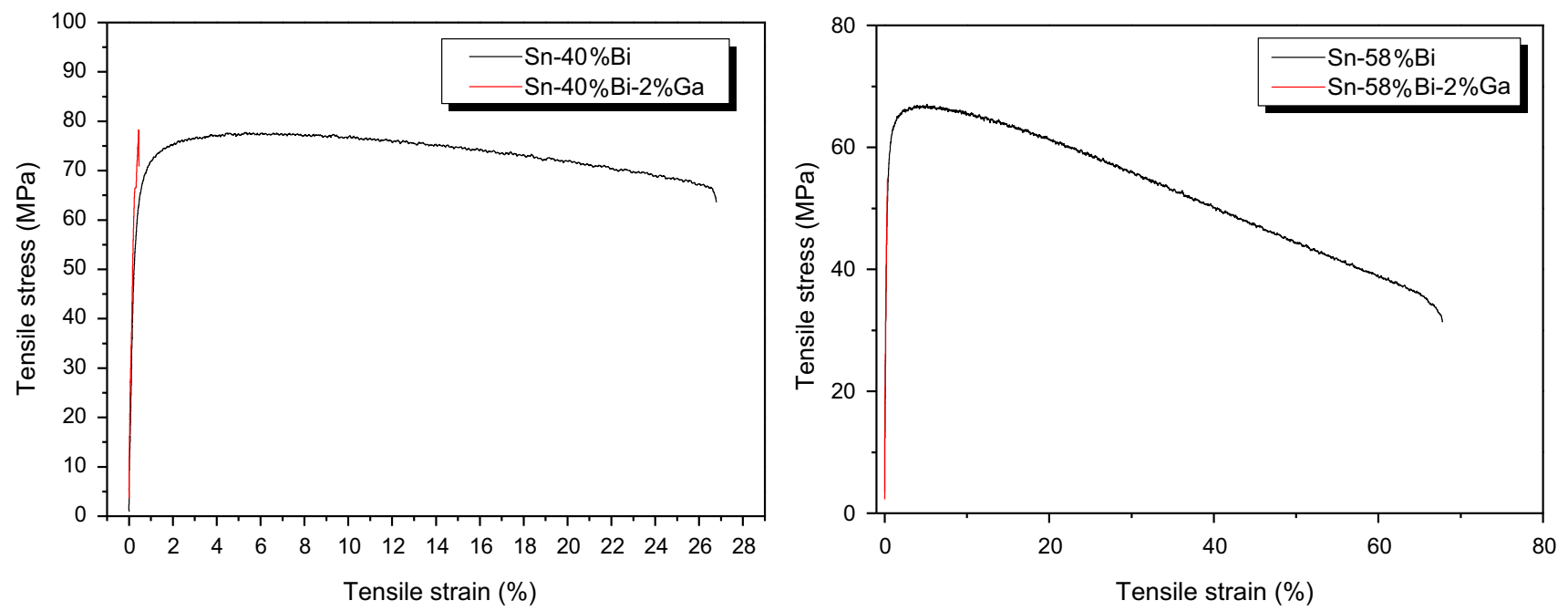

Fig. 18. Typical stress-strain plots for the Sn-40wt.\%Bi(-2wt.\%Ga) and Sn-58wt.\%Bi(-2wt.\%Ga) alloys.

layer considering heat-treated samples for $360 \mathrm{~h}$ at $100^{\circ} \mathrm{C}$, whereas the $\mathrm{Sn}-58 \mathrm{wt} . \% \mathrm{Bi}$ alloy had the thickest one.

It is worth noting that the $\mathrm{Cu}_{9} \mathrm{Ga}_{4}$ formation at the interface of the as-soldered alloys could minimize the formation of Ga-liquid phases, suppressing the major Ga-addition disadvantage. In this case, $\mathrm{Ga}$ additions could indeed be proposed as a good solution for the CuSn IMC suppression. Thermal conductivity experiments should be carried out in order to evaluate the $\mathrm{Cu}_{9} \mathrm{Ga}_{4}$ formation effects in the thermal resistance of the interface. This is the subject of an ongoing research.

\section{ACKNOWLEDGMENTS}

The authors are grateful to FAPESP (São Paulo Research Foundation, Brazil: Grant 2017/12741-6) for their financial support. This study was financed in part by the Coordenação de Aperfeiçoamento de Pessoal de Nível Superior-Brazil (CAPES).

\section{REFERENCES}

1. G.E. Moore, Electronics 38, 114 (1965).

2. G.E. Moore, in IEDM Technical Digest (1975), pp. 11-13.

3. S.E. Thompson and S. Parthasarathy, Mater. Today 9, 20 (2006).

4. R.S. Williams, Comput. Sci. Eng. 19, 7 (2017).

5. J. Hansson, C. Zanden, L. Ye, and J. Liu, in IEEE 16th International Conference on Nanotechnology (2016), pp. 371-374.

6. F. Sarvar, D. Whalley, and P. Conway, in 1st Electronics Systems-Intergration Technology Conference (2006), pp. $1292-1302$

7. K.M. Razeeb, E. Dalton, G.L.W. Cross, and A.J. Robinson, Int. Mater. Rev. 63, 1 (2018).

8. J.P. Gwinn and R.L. Webb, Microelectron. J. 34, 215 (2003).

9. A. Garcia and M. Prates, Metall. Trans. 9B, 449 (1978).
10. A. McWilliams, Thermal Interface Materials: Technologies, Applications and Global Markets (Wellesley: BCC Research, 2015), pp. 2-156.

11. R. Skuriat, J.F. Li, P.A. Agyakwa, N. Mattey, P. Evans, and C.M. Johnson, Microelectron. Reliab. 53, 1933 (2013).

12. R. Zhang, J. Cai, Q. Wang, J. Li, Y. Hu, H. Du, and L. Li, J. Electron. Packag. 136, 011012 (2014).

13. S.K. Lin, T.L. Nguyen, S.C. Wu, and Y.H. Wang, J. Alloys Compd. 586, 319 (2014).

14. V.C.E. Silva, B.L. Silva, J.E. Spinelli, and A. Garcia, J. Electron. Mater. 46, 1754 (2017).

15. B.L. Silva, A. Garcia, and J.E. Spinelli, J. Alloys Compd. 691, 600 (2017).

16. B.L. Silva, A. Garcia, and J.E. Spinelli, Mater. Charact. 114, 30 (2016).

17. K. Gryc, B. Smetana, M. Tkadlečková, M. Žaludová, K. Michalek, L. Socha, J. Dobrovská, K. Janiszewski, and P. Machovčák, Metabk 53, 295 (2014).

18. K. Gryc, M. Strouhalová, B. Smetana, M. Kawuloková, S. Zlá, L. Socha, K. Michalek, M. Tkadlečková, A. Kalup, P. Jonsta, and M. Sušovský, Metabk 56, 385 (2017).

19. W.L.R. Santos, B.L. Silva, F. Bertelli, J.E. Spinelli, N. Cheung, and A. Garcia, Appl. Therm. Eng. 107, 431 (2016).

20. B.L. Silva, F. Bertelli, M.V. Canté, J.E. Spinelli, N. Cheung, and A. Garcia, J. Mater. Sci.: Mater. Electron. 27, 1994 (2016).

21. B.L. Silva, N. Cheung, A. Garcia, and J.E. Spinelli, Mater. Lett. 142, 163 (2015).

22. E. Yang, H. Guo, J. Guo, J. Shang, and M. Wang, Acta Metall. Sin. (English Lett). 27, 290 (2014).

23. F. Wang, L. Zhou, X. Wang, and P. He, J. Alloys Compd. 688,639 (2016).

24. W.D. Callister and D.G. Rethwisch, Materials Science and Engineering: An Introduction (New York: Wiley, 2013).

25. L. Zang, Z. Yuan, H. Zhao, and X. Zhang, Mater. Lett. 63, 2067 (2009).

26. G.E. Dieter, Mechanical Metallurgy (New York: McGrawHill, 1976).

Publisher's Note Springer Nature remains neutral with regard to jurisdictional claims in published maps and institutional affiliations. 